\title{
Flora em estado de ameaça na llha Grande, Angra dos Reis, Rio de Janeiro, Brasil'
}

\author{
Lívia Correia Fróes² (1) \& Michaele Alvim Milward-de-Azevedo2,* (i) \\ 'Parte da monografia da primeira autora apresentada em 15 de dezembro de 2017, para o curso de Bacharelado \\ em Gestão Ambiental, Instituto Três Rios, Universidade Federal Rural do Rio de Janeiro. \\ ${ }^{2}$ Universidade Federal Rural do Rio de Janeiro, Instituto Três Rios, Laboratório de Diversidade Vegetal, \\ Av. Prefeito Alberto da Silva Lavinas, 1847, Centro, 25802-100, Três Rios, RJ \\ *Autor para correspondência: michaelemilward@gmail.com
}

Recebido em 31.1.2020

Aceito em 19.VII.2021

DOI 10.21826/2446-82312021v76e2021018

\begin{abstract}
RESUMO - A Ilha Grande, localizada em Angra dos Reis, Rio de Janeiro, é um dos remanescentes de Mata Atlântica, apresentando um mosaico de unidades de conservação, e em função de sua característica insular, constitui um ecossistema independente delimitado, apresentando biodiversidade vasta em endemismo e alta a vulnerabilidade. $\mathrm{O}$ conhecimento da flora apresenta grandes lacunas, devido à dificuldade de acesso à determinadas áreas e áreas muito alteradas pela ação antrópica. O objetivo deste trabalho foi gerar e avaliar as espécies da flora da Ilha Grande, pertencentes à Lista Vermelha. A lista de espécies foi baseada nos dados informados nos sítios eletrônicos dos herbários virtuais e literatura consultada. Foram encontradas um total de 84 espécies, entre elas cinco CR, 24 EN, $40 \mathrm{VU}$ e 15 NT, além disso, 18 com DD. Quatro destas espécies são encontradas nas trilhas de maior acesso pelos turistas e 12 são endêmicas do estado. Apenas 23 espécies apresentaram dados suficientes para a avaliação do seu grau de ameaça e, destas, 15 alteraram seus status para CR. A maioria das espécies foram registradas nas vertentes sul e sudeste da ilha. Este trabalho fornece subsídios para tomadas de decisões e criação de políticas públicas, em uma área prioritária para conservação.
\end{abstract}

Palavras-chave: biodiversidade, conservação, lista vermelha, turismo

ABSTRACT - Threatened flora in Ilha Grande, Angra dos Reis, Rio de Janeiro, Brazil. Ilha Grande, located in Angra dos Reis, Rio de Janeiro, is one remnant of Atlantic Forest, presenting a mosaic of conservation units, and due to its island characteristic, it constitutes a bounded independent ecosystem, presenting vast biodiversity in endemism and making the vulnerability. The knowledge of the flora has gaps, due to difficulty of access to certain areas and areas altered by anthropic action. The objective was to generate and evaluate the Flora species of Ilha Grande, belonging to the Red List. The species list was based on data reported on the websites of the virtual herbariums and consulted literature. A total of 84 species were found, among which five as CR, $24 \mathrm{EN}, 40 \mathrm{VU}$, and $15 \mathrm{NT}$, also, 18 with DD. Four of these species are found on the most accessible trails by tourists, and 12 are endemic of state. Only 23 species had sufficient data to assess their degree of threat to Ilha Grande, and 15 of these changed their status to $\mathrm{CR}$. The great majority of the species were recorded in the south and southeast sides of the island. This work provides subsidies to make decisions and create public policies, in a priority area for conservation.

Keywords: biodiversity, conservation, redlist, tourism

\section{INTRODUÇÃO}

A Mata Atlântica é uma das florestas com o maior número de espécies de animais e plantas por unidade de área, tendo entre $1 \%$ e $8 \%$ de toda flora e fauna mundiais (Marques et al. 2016). Das cerca de 33.000 espécies de Angiospermas registradas para o Brasil, aproximadamente 15.550 ocorrem neste domínio (BFG 2015, Marques et al. 2016, Flora do Brasil 2020), sendo que 8.443 são endêmicas e 1.544 estão ameaçadas de extinção (Marques et al. 2016). Juntamente com o Cerrado, a Mata Atlântica é um dos domínios fitogeográficos mais degradados e ameaçados do Brasil (Marques et al. 2016). No entanto, ao contrário dos outros, na Mata Atlântica a expansão urbana sem planejamento é considerada a principal causa da degradação florestal e ainda uma das suas maiores ameaças (Diegues 2000, Dean 2004, Scarano 2012, Loyola et al. 2014).

De acordo com a "Lista Nacional Oficial de Espécies da Flora Ameaçadas de Extinção", Portaria do Ministério do Meio Ambiente (MMA) No 443, de 17 de dezembro de 2014, o Brasil apresenta 2.113 espécies da sua flora ameaçadas de extinção (MMA 2014). O Rio de Janeiro, em conjunto com os estados de Minas Gerais e Espírito Santo, lidera a lista de espécies em risco de extinção (Coelho et al. 2017). Isso se deve especialmente ao modelo de exploração econômico e/ou dos recursos naturais empregado na região Sudeste por muitos anos, resultando em elevado grau de fragmentação e degradação do habitat, e que juntamente com os efeitos das mudanças climáticas e a perda da diversidade, resultou na vulnerabilidade da vegetação. $\mathrm{O}$ 
estado do Rio de Janeiro apresenta atualmente um total 8.204 espécies de angiospermas, 29 de gimnospermas, 872 de briófitas e 660 de samambaias e licófitas (Flora do Brasil 2020), e a sua lista de espécies endêmicas conta com 884 espécies, sendo que 513 foram consideradas como ameaçadas de extinção e 364 possuíam dados insuficientes "DD", impossibilitando sua avaliação do risco de extinção (Machado et al. 2018).

A Ilha Grande, localizada no sul do estado do Rio de Janeiro, no município de Angra dos Reis, é um dos importantes remanescentes de Mata Atlântica (NunesFreitas et al. 2009). Apontada como um dos maiores patrimônios naturais do estado do Rio de Janeiro, apresenta dois acontecimentos recentes que marcaram a sua história: a intensificação do fluxo turístico após a implosão do Instituto Penal Cândido Mendes (1994) e a instituição de leis ambientais com a criação de quatro unidades de conservação da natureza, que são: o Parque Estadual da Ilha Grande - PEIG (1971), a Reserva Biológica Estadual da Praia do Sul - RBEPS (1981), a Área de Proteção Ambiental de Tamoios - APA de Tamoios (1982) (Mendonça 2008) e a Reserva de Desenvolvimento Sustentável do Aventureiro - RDSA (2014). Cada unidade de conservação possui uma categoria distinta, apresentando características exclusivas quanto à preservação e uso do solo, principalmente quando relativo ao acesso público.

Em função de sua característica insular, a Ilha Grande constitui um ecossistema independente delimitado, apresentando biodiversidade vasta em endemismo e tornando alta a vulnerabilidade da fauna e flora local. Segundo Serafini et al. (2010), as ilhas são ambientes distintos e potencialmente mais vulneráveis, abrigando biodiversidade peculiar devido ao seu isolamento geográfico e apresentando grande número de espécies endêmicas. Todavia, as espécies exóticas invasoras são consideradas como uma das principais causas de perda de biodiversidade em ilhas, em decorrência da grande quantidade de espécies endêmicas e aos seus habitats restritos.

O objetivo deste trabalho foi gerar uma listagem da Flora da Ilha Grande, Angra dos Reis, Rio de Janeiro, pertencentes à Lista Vermelha, e avaliar o grau de endemismo, ameaça, assim como o valor ornamental e de interesse dessas espécies.

\section{MATERIAL E MÉTODOS}

\section{Área de estudo}

A Ilha Grande localiza-se no município de Angra dos Reis, litoral sudoeste do estado do Rio de Janeiro, entre as coordenadas $23^{\circ} 05^{\prime}-23^{\circ} 14^{\prime} \mathrm{S}$ e $44^{\circ} 05^{\prime}-44^{\circ} 23^{\prime} \mathrm{O}$, com aproximadamente $193 \mathrm{Km}^{2}$ (Fig. 1), representando a maior ilha do estado do Rio de Janeiro e a terceira do Brasil (Gama et al. 2006).

Isolada do continente por um canal com cerca de 2 $\mathrm{km}$ de largura, suas características físicas são semelhantes às observadas na Serra do Mar, com algumas montanhas atingindo aproximadamente $1.000 \mathrm{~m}$ de altitude (Esbérard et al. 2006). Os picos mais elevados são Pedra d'Água (1.031 m), Pico do Papagaio (959 m) e Morro do Ferreira (735 $\mathrm{m})$. As declividades variam de $21^{\circ}$, na vertente continental, a mais de $80^{\circ}$ em alguns pontos, conferindo aos cursos d'água a possibilidade de cheias e erosão intensa (Vallejo 2005, Gama et al. 2009).
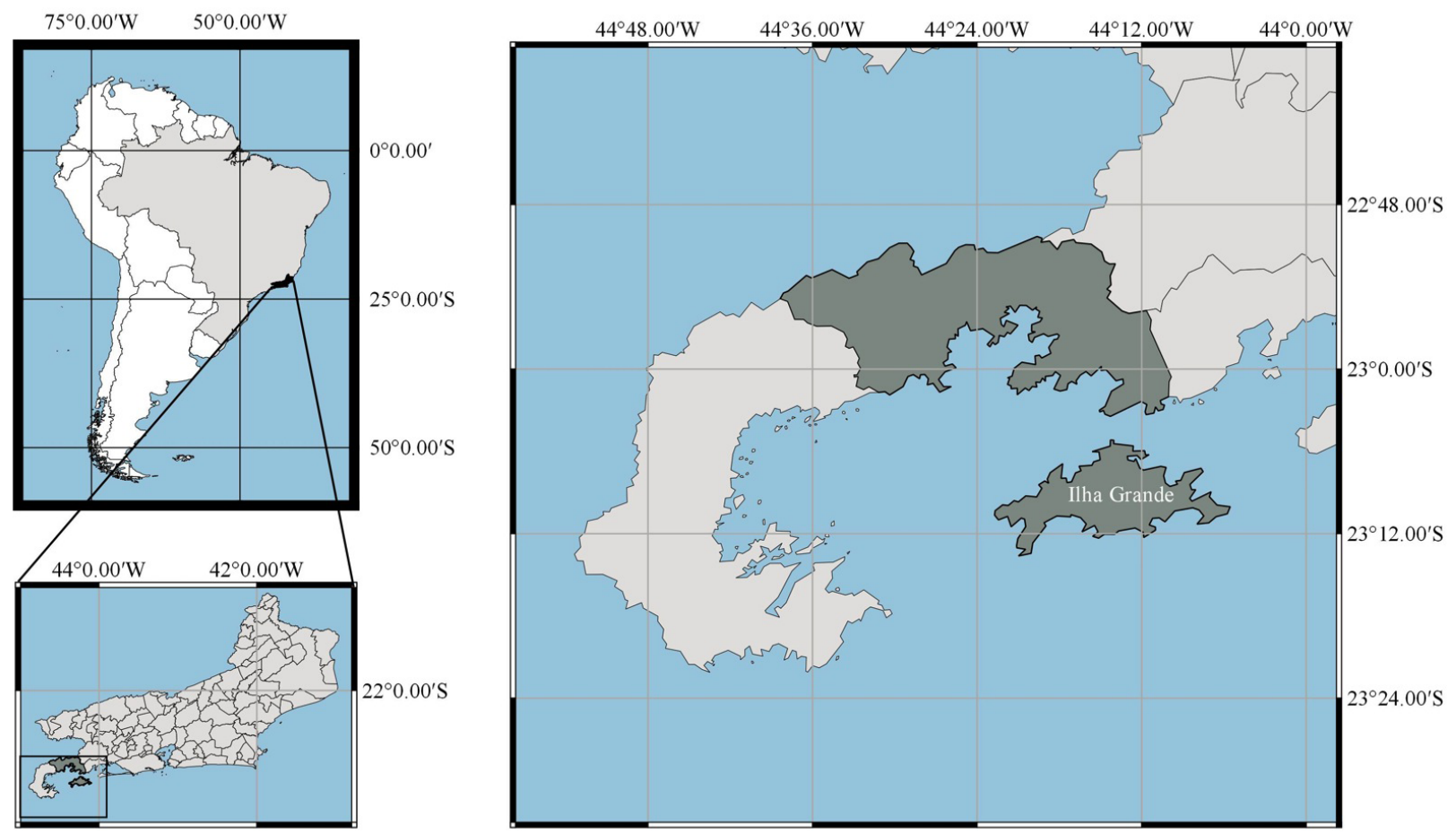

Figura 1. Mapa evidenciando a Ilha Grande, Angra dos Reis, Rio de Janeiro, Brasil. 
Possui clima tropical, quente e úmido, sem estação seca, e com temperatura média variando entre $15{ }^{\circ} \mathrm{C}$ e $30^{\circ} \mathrm{C}$ (Araújo et al. 2005), podendo as médias de temperatura máxima serem superiores a $30{ }^{\circ} \mathrm{C}$ no mês de fevereiro (Salgado \& Vasquez 2009). Situa-se no domínio de Mata Atlântica, apresentando fitofisionomia de Floresta Ombrófila Densa, Restinga e Mangue (Magalhães 2008, IBGE 2012), possuindo diferentes níveis de regeneração (Antonini \& Nunes-Freitas 2004). Em função do espraiamento de roças de subsistência de populações caiçaras e, principalmente, das áreas de regeneração de roças abandonadas, a paisagem é formada por mosaicos de tratos de florestas secundárias em diferentes idades sucessionais, de acordo com a época de abandono para pousio (Oliveira \& Coelho Netto 2001).

\section{Metodologia}

Primeiramente realizou-se um levantamento geral das espécies ocorrentes na Ilha Grande por meio de levantamento bibliográfico, visualização do acervo digital dos materiais depositados nos herbários nos sítios eletrônicos do Species Link (http://splink.cria.org.br/) e JABOT (http://aplicacoes. jbrj.gov.br/jabot/v2/consulta.php), seguido na checagem destas espécies no banco de dados do Centro Nacional de Conservação da Flora-CNCFlora (http://cncflora.jbrj.gov. br/portal), Flora do Brasil 2020 (http://floradobrasil.jbrj. gov.br/), Catálogo da Flora do estado do Rio de Janeiro (Baumgratz et al. 2014 - https://florariojaneiro.jbrj.gov. br/consulta.php) e Fundação Biodiversitas (http://www. biodiversitas.org.br/), assim como na literatura consultada: Martinelli \& Moraes (2013), Martinelli et al. (2018) e Maurenza et al. (2018). A lista de espécies da flora da Ilha Grande, pertencente à lista vermelha, assim como a obtenção dos dados geográficos de ocorrência das espécies, foram gerados baseado nestes dados. O levantamento das espécies nos herbários, foi realizado baseados em materiais identificados por especialistas das famílias botânicas. Os acrônimos dos herbários estão de acordo com Thiers (2020).

Os critérios utilizados foram baseados nas categorias estabelecidas pela IUCN (União Internacional para a Conservação da Natureza) (IUCN 2017): Extinta (EX), Extinta da natureza (EW), Regionalmente extinta (RE), Criticamente em perigo (CR), Em perigo (EN), Vulnerável (VU), Quase ameaçada (NT), Menos preocupante (LC), Dados insuficientes (DD) e Não aplicável (NA).

Após o levantamento das espécies pertencentes à lista vermelha da flora da Ilha Grande, a listagem foi conferida no Anexo I da Instrução Normativa $n^{\circ} 6$, de 23 de setembro de 2008 (MMA 2008) e na Lista Oficial de Espécies da Flora Ameaçadas de Extinção, publicada pela Portaria MMA n 443, de 17 de dezembro de 2014 (MMA 2014), sendo conferido o grau de ameaça apresentado nestas listagens oficiais da flora brasileira.
Os nomes atualmente aceitos, assim como, o tipo de hábito das espécies, fitofisionomia em que podem ocorrer, e se as espécies são endêmicas ou não do estado do Rio de Janeiro, foram verificados no sítio eletrônico da Flora do Brasil 2020 (http://floradobrasil.jbrj.gov.br/).

As avaliações do valor ornamental e do interesse das espécies foi consultado em: Bourscheid et al. (2011), Capellari Jr. (2002), CNCFlora (2012), Costa et al. (2006), Grings \& Brack (2011), Lorenzi (2002a, 2002b, 2009, 2010), Lorenzi \& Souza (2008) e Martinelli \& Moraes (2013).

Os dados geográficos das espécies foram plotados usando o sítio eletrônico SimpleMappr (http://www. simplemappr.net/), para análise da distribuição das mesmas na Ilha Grande.

O cálculo da Área de Ocupação (AOO) e Extensão de Ocorrência (EOO) das espécies pertencentes à Lista Vermelha ocorrentes na Ilha Grande foi realizado utilizando a ferramenta GeoCAT (http://geocat.kew.org/editor), utilizando o Grid de $2 \mathrm{~km}$, conforme recomendado pela IUCN (2017).

\section{RESULTADOS}

Foram verificadas 84 espécies, referentes à 39 famílias e 66 gêneros (Tabs. 1,2), ocorrentes nas vertentes sul, sudeste e leste da Ilha Grande (Fig. 2), pertencentes à Lista Vermelha, entre elas cinco Criticamente em Perigo (CR), 24 Em Perigo (EN), 40 Vulneráveis (VU) e 15 Quase Ameaçadas (NT). Deste total, aproximadamente 88\% correspondem a espécies endêmicas da Mata Atlântica, e apenas dez espécies não são exclusivas do bioma: Cedrela fissilis Vell. (Meliaceae), Cedrela odorata L. (Meliaceae), Coussapoa curranii S.F.Blake (Urticaceae), Euterpe edulis Mart. (Arecaceae), Mikania argyreiae DC. (Asteraceae), Melanopsidium nigrum Colla (Rubiaceae), Monstera praetermissa E.G.Gonç. \& Temponi (Araceae), Ocotea odorifera (Vell.) Rowher (Lauraceae), Octomeria alexandri Schltr. (Orchidaceae) e Rudgea jasminoides (Cham.) Müll.Arg. (Rubiaceae).

Cerca de $93 \%$ das espécies avaliadas são endêmicas do Brasil (78 espécies), e 14\% (12 espécies) são endêmicas do estado do Rio de Janeiro: Acianthera subrotundifolia (Cogn.) F.Barros \& V.T.Rodrigues (Orchidaceae), Anthurium luschnathianum Kunth (Araceae), Bertolonia valenteana Baumgratz (Melastomataceae), Cheilanthes incisa Kunze ex Mett. (Pteridaceae), Couratari pyramidata (Vell.) Kunth (Lecythidaceae), Meriania glazioviana Cogn. (Melastomataceae), Meriania longipes Triana (Melastomataceae), Miconia gigantea Cogn. (Melastomtaceae), Pleroma thereminiana (DC.) Triana (Melastomataceae), Rudgea macrophylla Benth (Rubiaceae), Stelis palmeiraensis Barb.Rodr. (Orchidaceae) e Vriesea rubyae E.Pereira (Bromeliaceae) (Tabs. 1, 2). 


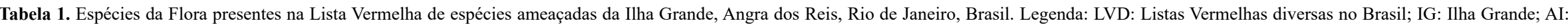

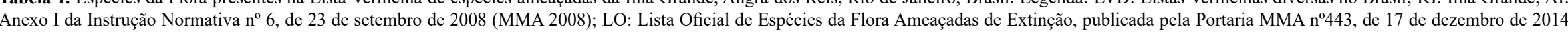

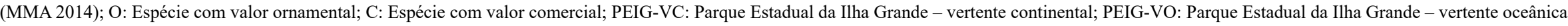

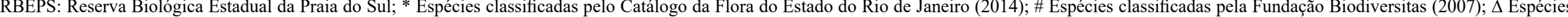

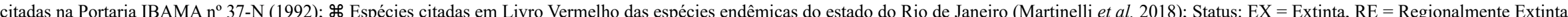
$\mathrm{CR}=$ Criticamente em Perigo, EN = Em Perigo, $\mathrm{VU}=$ Vulnerável e $\mathrm{NT}=$ Quase Ameaçada; Hábito: $\mathrm{AR}=$ arbóreo, $\mathrm{HE}=$ herbáceo, $\mathrm{AB}=$ arbustivo, $\mathrm{SB}=$ subarbustivo, TP = trepadeira e LI = liana

\begin{tabular}{|c|c|c|c|c|c|c|c|c|c|c|c|c|c|c|c|}
\hline $\begin{array}{l}\text { Status } \\
\text { Atual }\end{array}$ & $\begin{array}{l}\text { Status } \\
\text { LVD }\end{array}$ & $\begin{array}{l}\text { Status } \\
\text { IG }\end{array}$ & Família & Espécie & Hábito & AI & LO & $\begin{array}{l}\text { Endêmica } \\
\text { RJ }\end{array}$ & $\begin{array}{l}\text { Endêmica } \\
\text { Brasil }\end{array}$ & $\mathrm{O}$ & $\mathrm{C}$ & Referências & $\begin{array}{c}\text { PEIG } \\
\text { VC }\end{array}$ & $\begin{array}{c}\text { PEIG } \\
\text { VO }\end{array}$ & RBEPS \\
\hline $\mathrm{CR}$ & $\mathrm{CR}$ & - & Bignoniaceae & $\begin{array}{l}\text { Adenocalymma } \\
\text { ubatubense Assis \& Semir }\end{array}$ & LI & $\mathrm{X}$ & $\mathrm{X}$ & & $\mathrm{X}$ & & & D.N.S. Machado 372 (RB), Andrade (2015) & & $\mathrm{X}$ & \\
\hline $\mathrm{CR}$ & EN & - & Bromeliaceae & Vriesea rubyae E.Pereira & $\mathrm{HE}$ & & $\mathrm{X}$ & $\mathrm{X}$ & $\mathrm{X}$ & $\mathrm{X}$ & & $\begin{array}{l}\text { R. Moura } 973 \text { (RBvb); Callado et al. (2009); Costa et } \\
\text { al. (2018); Maurenza et al. (2018); Nunes-Freitas et } \\
\text { al. (2009) }\end{array}$ & $\mathrm{X}$ & & \\
\hline CR & - & - & Cyperaceae & $\begin{array}{l}\text { Pleurostachys pilulifera } \\
\text { Longhi-Wagner, Baldini } \\
\text { \& A.C.Araújo }\end{array}$ & $\mathrm{HE}$ & & $\mathrm{X}$ & & $\mathrm{X}$ & & & Manão (2011); Maurenza et al. (2018) & & $\mathrm{X}$ & \\
\hline $\mathrm{CR}$ & - & $\mathrm{CR}$ & Melastomataceae & $\begin{array}{l}\text { If Bertolonia valenteana } \\
\text { Baumgratz }\end{array}$ & $\mathrm{HE}$ & & & $\mathrm{X}$ & $\mathrm{X}$ & & & $\begin{array}{l}\text { A.A.M. de Barros } 3462 \text { (RFFP); A.A.M. de Barros } \\
3653 \text { (RFFP); H.C. de Lima } 5776 \text { (FLOR, RB); J.P.P. } \\
\text { Carauta } 2971 \text { (MBM, US); Baumgratz et al. (2018) }\end{array}$ & $\mathrm{X}$ & & \\
\hline $\mathrm{CR}$ & - & - & Pteridaceae & $\begin{array}{l}\text { \# Cheilanthes } \\
\text { incisa Kunze ex Mett. }\end{array}$ & $\mathrm{HE}$ & $\mathrm{X}$ & $\mathrm{X}$ & $\mathrm{X}$ & $\mathrm{X}$ & & & Callado et al. (2009) & & & \\
\hline EN & - & $\mathrm{CR}$ & Amaryllidaceae & $\begin{array}{l}\text { Hippeastrum striatum } \\
\text { (Lam.) Moore }\end{array}$ & $\mathrm{HE}$ & & $\mathrm{X}$ & & & $X$ & $\mathrm{X}$ & $\begin{array}{l}\text { L.C.Giordano et al. } 267 \text { (RB); Manão (2011); } \\
\text { Maurenza et al. (2018) }\end{array}$ & $X$ & $X$ & \\
\hline EN & - & EN & Araceae & $\begin{array}{l}\text { Anthurium } \\
\text { luschnathianum Kunth }\end{array}$ & $\mathrm{HE}$ & $\mathrm{X}$ & $\mathrm{X}$ & $\mathrm{X}$ & $\mathrm{X}$ & & & $\begin{array}{l}\text { M. Nadruz } 1165 \text { (RB); M. Nadruz } 1171 \text { (RB); Araújo } \\
\text { \& Oliveira (1988); Maurenza et al. (2018); Nadruz et } \\
\text { al. (2018) }\end{array}$ & & $\mathrm{X}$ & $\mathrm{X}$ \\
\hline $\mathrm{EN}$ & - & - & Begoniaceae & Begonia undulata Schott & SB & & $\mathrm{X}$ & & $\mathrm{X}$ & & & $\begin{array}{l}\text { A.A.M. de Barros } 1345 \text { (RFFP); Manão (2011); } \\
\text { Maurenza et al. (2018) }\end{array}$ & & $\mathrm{X}$ & \\
\hline EN & - & - & Bignoniaceae & $\begin{array}{l}\text { Tabebuia cassinoides } \\
\text { (Lam.) DC. }\end{array}$ & $\mathrm{AR}$ & & $\mathrm{X}$ & & $\mathrm{X}$ & & & Maurenza et al. (2018) & & & \\
\hline EN & $\begin{array}{l}\text { EX/ } \\
\text { VU }\end{array}$ & - & Bromeliaceae & $\begin{array}{l}\text { Neoregelia } \\
\text { hoehneana L.B.Sm. }\end{array}$ & $\mathrm{HE}$ & & $\mathrm{X}$ & & $\mathrm{X}$ & & & $\begin{array}{l}\text { A.F. Nunes-Freitas } 62 \text { (RBR); A.F. Nunes-Freitas } 63 \\
\text { (RBR); Almeida et al. (1998); Callado et al. (2009); } \\
\text { Nunes-Freitas et al. (2009) }\end{array}$ & & $\mathrm{X}$ & $\mathrm{X}$ \\
\hline EN & - & $\mathrm{CR}$ & Bromeliaceae & $\begin{array}{l}\text { Wittrockia superba } \\
\text { Lindm. }\end{array}$ & $\mathrm{HE}$ & & $\mathrm{X}$ & & $\mathrm{X}$ & & & $\begin{array}{l}\text { A.F. Nunes-Freitas } 28 \text { (RBR); A.F. Nunes-Freitas } 94 \\
\text { (RBR); Callado et al. (2009); Nunes-Freitas et al. } \\
\text { (2009) }\end{array}$ & $\mathrm{X}$ & $\mathrm{X}$ & \\
\hline EN & - & - & Chrysobalanaceae & Couepia schottii Fritsch & $\mathrm{AR}$ & & $\mathrm{X}$ & & $\mathrm{X}$ & & & $\begin{array}{l}\text { Callado et al. (2009); Oliveira (2002); Maurenza et } \\
\text { al. (2018) }\end{array}$ & $X$ & & \\
\hline
\end{tabular}


Tabela 1. Cont

\begin{tabular}{|c|c|c|c|c|c|c|c|c|c|c|c|c|c|c|c|}
\hline $\begin{array}{l}\text { Status } \\
\text { Atual }\end{array}$ & $\begin{array}{l}\text { Status } \\
\text { LVD }\end{array}$ & $\begin{array}{l}\text { Status } \\
\text { IG }\end{array}$ & Família & Espécie & Hábito & AI & LO & $\begin{array}{l}\text { Endêmica } \\
\text { RJ }\end{array}$ & $\begin{array}{l}\text { Endêmica } \\
\text { Brasil }\end{array}$ & $\mathrm{O}$ & $\mathrm{C}$ & Referências & $\begin{array}{l}\text { PEIG } \\
\text { VC }\end{array}$ & $\begin{array}{l}\text { PEIG } \\
\text { VO }\end{array}$ & RBEPS \\
\hline EN & VU & - & Elaeocarpaceae & $\begin{array}{l}\text { Sloanea } \\
\text { obtusifolia (Moric.) } \\
\text { Schum. }\end{array}$ & $\mathrm{AR}$ & & $\mathrm{X}$ & & $\mathrm{X}$ & & $\mathrm{X}$ & Araújo \& Oliveira (1988) & & & $\mathrm{X}$ \\
\hline EN & $\begin{array}{l}\mathrm{CR} / \\
\mathrm{VU}\end{array}$ & - & Lauraceae & $\begin{array}{l}\text { Ocotea odorifera (Vell.) } \\
\text { Rowher }\end{array}$ & $\mathrm{AR}$ & $\mathrm{X}$ & $\mathrm{X}$ & & $\mathrm{X}$ & & $\mathrm{X}$ & L.P.G. Rosa s.n. (HRJ 12334) & - & - & - \\
\hline EN & - & - & Lecythidaceae & $\begin{array}{l}\text { Couratari pyramidata } \\
\text { (Vell.) Kunth }\end{array}$ & $\mathrm{AR}$ & & $\mathrm{X}$ & $\mathrm{X}$ & $\mathrm{X}$ & & $\mathrm{X}$ & F. Pinheiro et al. 809 (HB) & & $\mathrm{X}$ & \\
\hline EN & EN & - & Marantaceae & Ischnosiphon ovatus Körn & $\mathrm{HE}$ & & $\mathrm{X}$ & & $\mathrm{X}$ & & & $\begin{array}{l}\text { A.A.M. de Barros } 4414 \text { (RFFP); Manão (2011); } \\
\text { Maurenza et al. (2018) }\end{array}$ & & $\mathrm{X}$ & \\
\hline EN & - & - & Melastomataceae & $\begin{array}{l}\text { If Meriania glazioviana } \\
\text { Cogn. }\end{array}$ & $\mathrm{AR}$ & & & $\mathrm{X}$ & $\mathrm{X}$ & & & $\begin{array}{l}\text { A.A.M. de Barros } 1428 \text { (RB); R. Ribeiro } 668 \text { (US); } \\
\text { Baumgratz et al. (2018) }\end{array}$ & & $\mathrm{X}$ & $\mathrm{X}$ \\
\hline EN & - & $\mathrm{CR}$ & Melastomataceae & $\begin{array}{l}\text { H Meriania longipes } \\
\text { Triana }\end{array}$ & $\mathrm{AR}$ & & & $\mathrm{X}$ & $\mathrm{X}$ & & & $\begin{array}{l}\text { A.A.M. de Barros } 5368 \text { (RFFP); F.C. Pinheiro } 367 \\
\text { (RB); T.S. Mendes } 39 \text { (RFFP); Baumgratz et al. } \\
\text { (2018) }\end{array}$ & $\mathrm{X}$ & $\mathrm{X}$ & \\
\hline EN & - & - & Melastomataceae & * Miconia gigantea Cogn. & $\mathrm{AR}$ & & & $\mathrm{X}$ & $\mathrm{X}$ & & & A.T. Silva s.n. (RBR 32976); Baumgratz et al. (2018) & $\mathrm{X}$ & & \\
\hline EN & - & $\mathrm{CR}$ & Melastomataceae & $\begin{array}{l}\text { If Pleroma thereminiana } \\
\text { (DC.) Triana }\end{array}$ & $\mathrm{AR}$ & & & $\mathrm{X}$ & $\mathrm{X}$ & & & $\begin{array}{l}\text { A.A.M. de Barros } 1156 \text { (RFFP); A.A.M. de Barros } \\
1373 \text { (RFFP); A.A.M. de Barros } 4023 \text { (RFFP); F.C. } \\
\text { Pinheiro } 419 \text { (RB); Baumgratz et al. (2018); Callado } \\
\text { et al. (2009); Manão (2011) }\end{array}$ & $\mathrm{X}$ & $\mathrm{X}$ & \\
\hline EN & EN & - & Monimiaceae & $\begin{array}{l}\Delta \text { Mollinedia glabra } \\
\text { (Sprengel) Perkins }\end{array}$ & $\mathrm{SB} / \mathrm{AR}$ & $\mathrm{X}$ & & & $\mathrm{X}$ & & & Callado et al. (2009); Manão (2011) & & $\mathrm{X}$ & \\
\hline EN & EN & - & Myristicaceae & $\begin{array}{l}\text { Virola bicuhyba (Schott ex } \\
\text { Spreng.) Warb. }\end{array}$ & $\mathrm{AR}$ & $\mathrm{X}$ & $\mathrm{X}$ & & $\mathrm{X}$ & & $\mathrm{X}$ & L.P.G. Rosa s.n. (HRJ 12357); Maurenza et al. (2018) & & & \\
\hline EN & - & - & Myrtaceae & $\begin{array}{l}\text { Eugenia malacantha } \\
\text { D.Legrand }\end{array}$ & $\mathrm{AR}$ & $\mathrm{X}$ & & & $\mathrm{X}$ & & & A. Giaretta 1491 (SPF) & $\mathrm{X}$ & & \\
\hline $\mathrm{EN}$ & VU & - & Orchidaceae & $\begin{array}{l}\text { Octomeria alexandri } \\
\text { Schltr. }\end{array}$ & $\mathrm{HE}$ & & $\mathrm{X}$ & & $\mathrm{X}$ & & & Cruz \& Nunes-Freitas (2017); Maurenza et al. (2018) & & & $\mathrm{X}$ \\
\hline $\mathrm{EN}$ & $\mathrm{CR}$ & - & Orchidaceae & Rauhiella silvana Toscano & $\mathrm{HE}$ & & $\mathrm{X}$ & & $\mathrm{X}$ & $\mathrm{X}$ & & Cruz \& Nunes-Freitas (2017); Maurenza et al. (2018) & & & $\mathrm{X}$ \\
\hline EN & - & - & Rubiaceae & $\begin{array}{l}\text { \# Rudgea interrupta } \\
\text { Benth. }\end{array}$ & $\mathrm{SB} / \mathrm{AR}$ & $\mathrm{X}$ & & & $\mathrm{X}$ & & & Manão (2011) & & $\mathrm{X}$ & \\
\hline EN & - & $\mathrm{CR}$ & Rubiaceae & $\begin{array}{l}\text { Rudgea } \\
\text { macrophylla Benth. }\end{array}$ & SB & $\mathrm{X}$ & $\mathrm{X}$ & $\mathrm{X}$ & $\mathrm{X}$ & & & $\begin{array}{l}\text { R. Ribeiro et W. L. Araujo } 1905 \text { (RB); Maurenza et } \\
\text { al. (2018) }\end{array}$ & & & $\mathrm{X}$ \\
\hline EN & - & - & Sapotaceae & $\begin{array}{l}\text { Pradosia kuhlmannii } \\
\text { Toledo }\end{array}$ & $\mathrm{AR}$ & & $\mathrm{X}$ & & $\mathrm{X}$ & & & $\begin{array}{l}\text { Oliveira (2002); Callado et al. (2009); Maurenza et } \\
\text { al. (2018) }\end{array}$ & $\mathrm{X}$ & & \\
\hline
\end{tabular}


Tabela 1. Cont

\begin{tabular}{|c|c|c|c|c|c|c|c|c|c|c|c|c|c|c|c|}
\hline $\begin{array}{l}\text { Status } \\
\text { Atual }\end{array}$ & $\begin{array}{c}\text { Status } \\
\text { LVD }\end{array}$ & $\begin{array}{c}\text { Status } \\
\text { IG }\end{array}$ & Família & Espécie & Hábito & AI & LO & $\begin{array}{l}\text { Endêmica } \\
\text { RJ }\end{array}$ & $\begin{array}{c}\text { Endêmica } \\
\text { Brasil }\end{array}$ & $\mathrm{O}$ & $\mathrm{C}$ & Referências & $\begin{array}{l}\text { PEIG } \\
\text { VC }\end{array}$ & $\begin{array}{l}\text { PEIG } \\
\text { VO }\end{array}$ & RBEPS \\
\hline EN & - & - & Smilacaceae & Smilax spicta Vell. & LI & & $\mathrm{X}$ & & $\mathrm{X}$ & & & $\begin{array}{l}\text { A.A.M. de Barros } 4020 \text { (RFFP); Andrade } \\
(2015)\end{array}$ & & $\mathrm{X}$ & \\
\hline VU & - & - & Araceae & $\begin{array}{l}\text { * Monstera praetermissa } \\
\text { E.G.Gonç. \& Temponi }\end{array}$ & $\mathrm{HE}$ & & & & $\mathrm{X}$ & & & Nadruz et al. (2014) & & & $\mathrm{X}$ \\
\hline VU & $\begin{array}{l}\mathrm{EN} / \\
\mathrm{VU}\end{array}$ & $\mathrm{CR}$ & Arecaceae & Euterpe edulis Mart. & $\mathrm{AR}$ & $\mathrm{X}$ & $\mathrm{X}$ & & & & $\mathrm{X}$ & $\begin{array}{l}\text { Araújo \& Oliveira (1988); Callado et al. (2009); } \\
\text { Maurenza et al. (2018) }\end{array}$ & & & $\mathrm{X}$ \\
\hline VU & $\begin{array}{l}\mathrm{RE} / \\
\mathrm{VU}\end{array}$ & $\mathrm{CR}$ & Aristochiaceae & Aristolochia odora Steud. & LI & & $\mathrm{X}$ & & $\mathrm{X}$ & $\mathrm{X}$ & $\mathrm{X}$ & $\begin{array}{l}\text { O. Yano, M.I.M.N. Oliveira et Silva } 23541 \text { (SP); E. J. } \\
\text { Lirio et al. } 1199 \text { (RB); Maurenza et al. (2018) }\end{array}$ & $X$ & & \\
\hline VU & - & $\mathrm{CR}$ & Asteraceae & Mikania argyreiae DC. & LI & & $\mathrm{X}$ & & $X$ & & & $\begin{array}{l}\text { D. Pedrosa et H.Q.B. Fernandes } 920 \text { (US); J.P.P. } \\
\text { Carauta } 2931 \text { (RB); R. Scheel-Ybert et al. } 264 \text { (RB); } \\
\text { Andrade (2015); Callado et al. (2009); Manão (2011); } \\
\text { Maurenza et al. (2018) }\end{array}$ & $\mathrm{X}$ & $\mathrm{X}$ & $\mathrm{X}$ \\
\hline VU & EN & - & Begoniaceae & $\begin{array}{l}\text { Begonia curtii L.B.Sm. \& } \\
\text { B.G.Schub }\end{array}$ & SB & & $\mathrm{X}$ & & $\mathrm{X}$ & & & $\begin{array}{l}\text { M.V.S Alves et D.S.D. Araujo } 360 \text { (RB); Callado et al. } \\
\text { (2009); Manão (2011); Maurenza et al. (2018) }\end{array}$ & & $X$ & $\mathrm{X}$ \\
\hline VU & $\begin{array}{l}\mathrm{RE} / \\
\mathrm{EN}\end{array}$ & $\mathrm{CR}$ & Bromeliaceae & $\begin{array}{l}\text { * Aechmea gracilis } \\
\text { Lindm. }\end{array}$ & $\mathrm{HE}$ & & & & $\mathrm{X}$ & & & $\begin{array}{l}\text { A.F. Nunes-Freitas } 40 \text { (RBR); A.F. Nunes-Freitas } 86 \\
\text { (RBR); A.F. Nunes-Freitas } 87 \text { (RBR); A.F. Nunes- } \\
\text { Freitas } 89 \text { (RBR); C.F.D. Rocha } 17 \text { (RBR); Almeida } \\
\text { et al. (1988); Araújo \& Oliveira (1988); Callado et } \\
\text { al. (2009); Nunes-Freitas (2004); Nunes-Freitas et al. } \\
\text { (2009); Manão (2011); Moura \&Vieira (2014) }\end{array}$ & & $X$ & $\mathrm{X}$ \\
\hline VU & VU & - & Bromeliaceae & $\begin{array}{l}\text { \# Neoregelia cruenta } \\
\text { (R.Graham) L.B.Sm. }\end{array}$ & $\mathrm{HE}$ & & & & $\mathrm{X}$ & $X$ & & $\begin{array}{l}\text { Araújo \& Oliveira (1988); Callado et al. (2009); } \\
\text { Nunes-Freitas et al. (2009) }\end{array}$ & & & $\mathrm{X}$ \\
\hline VU & VU & - & Bromeliaceae & $\begin{array}{l}\text { Nidularium serratum } \\
\text { Leme }\end{array}$ & $\mathrm{HE}$ & & $\mathrm{X}$ & & $\mathrm{X}$ & & & Araújo \& Oliveira (1988) & & & $\mathrm{X}$ \\
\hline VU & - & - & Bromeliaceae & $\begin{array}{l}\text { \# Vriesea bituminosa } \\
\text { Wawra }\end{array}$ & $\mathrm{HE}$ & & & & $\mathrm{X}$ & $\mathrm{X}$ & & Callado et al. (2009); Nunes-Freitas et al. (2009) & & & \\
\hline VU & $\begin{array}{l}\mathrm{EN} / \\
\mathrm{VU}\end{array}$ & - & Bromeliaceae & $\begin{array}{l}\text { *Vriesea neoglutinosa } \\
\text { Mez }\end{array}$ & $\mathrm{HE}$ & & & & $\mathrm{X}$ & $\mathrm{X}$ & & $\begin{array}{l}\text { A.F. Nunes-Freitas } 804 \text { (RBR); Callado et al. (2009); } \\
\text { Manão (2011); Moura \& Vieira (2014) }\end{array}$ & & $\mathrm{X}$ & $\mathrm{X}$ \\
\hline VU & - & $\mathrm{CR}$ & Bromeliaceae & $\begin{array}{l}\text { * Vriesea rodigasiana } \\
\text { E.Morren }\end{array}$ & $\mathrm{HE}$ & & & & $X$ & $\mathrm{X}$ & & $\begin{array}{l}\text { A.C.R. Cruz } 20 \text { (RBR); A.C.R. Cruz } 28 \text { (RBR); Araújo } \\
\text { \& Oliveira (1988); Callado et al. (2009); Nunes- } \\
\text { Freitas (2004); Nunes-Freitas et al. (2006); Nunes- } \\
\text { Freitas et al. (2009) }\end{array}$ & & & $\mathrm{X}$ \\
\hline VU & - & - & Cactaceae & Rhipsalis oblonga Loefgr. & SB & & & & $\mathrm{X}$ & $\mathrm{X}$ & & $\begin{array}{l}\text { A.A.M. de Barros } 3418 \text { (RFFP); A.A.M. de Barros } \\
4815 \text { (RFFP); A.A.M. de Barros } 5482 \text { (RFFP); P.C. } \\
\text { Porto 109 (RB); Araújo \& Oliveira (1988); Callado et } \\
\text { al. (2009); Manão (2011) }\end{array}$ & & $\mathrm{X}$ & $\mathrm{X}$ \\
\hline
\end{tabular}


Tabela 1. Cont.

\begin{tabular}{|c|c|c|c|c|c|c|c|c|c|c|c|c|c|c|c|}
\hline $\begin{array}{l}\text { Status } \\
\text { Atual }\end{array}$ & $\begin{array}{l}\text { Status } \\
\text { LVD }\end{array}$ & $\begin{array}{l}\text { Status } \\
\text { IG }\end{array}$ & Família & Espécie & Hábito & $\mathrm{AI}$ & LO & $\begin{array}{l}\text { Endêmica } \\
\text { RJ }\end{array}$ & $\begin{array}{l}\text { Endêmica } \\
\text { Brasil }\end{array}$ & $\mathrm{O}$ & $\mathrm{C}$ & Referências & $\begin{array}{l}\text { PEIG } \\
\text { VC }\end{array}$ & $\begin{array}{l}\text { PEIG } \\
\text { VO }\end{array}$ & RBEPS \\
\hline VU & - & - & Euphorbiaceae & $\begin{array}{l}\text { * Euphorbia insulana } \\
\text { Vell. }\end{array}$ & $\mathrm{HE}$ & & & & & & & Oliveira (2014) & & & $\mathrm{X}$ \\
\hline VU & - & - & Fabaceae & Inga platyptera Benth. & $\mathrm{AR}$ & & $\mathrm{X}$ & & $\mathrm{X}$ & & & Maurenza et al. (2018) & & & \\
\hline VU & EN & - & Gesneriaceae & $\begin{array}{l}\text { Codonanthe carnosa } \\
\text { (Gardner) Hanst. }\end{array}$ & $\mathrm{HE}$ & & $\mathrm{X}$ & & $\mathrm{X}$ & & & Araújo \& Oliveira (1988); Callado et al. (2009) & & $\mathrm{X}$ & $\mathrm{X}$ \\
\hline VU & - & - & Heliconiaceae & $\begin{array}{l}\Delta \text { Heliconia farinosa } \\
\text { Raddi }\end{array}$ & $\mathrm{HE}$ & $\mathrm{X}$ & & & $\mathrm{X}$ & $\mathrm{X}$ & & Araújo \& Oliveira (1988); Callado et al. (2009) & & & $\mathrm{X}$ \\
\hline VU & VU & - & Lauraceae & $\begin{array}{l}\text { Urbanodendron bahiense } \\
\text { (Meisn.) Rohwer }\end{array}$ & $\mathrm{AR}$ & & $\mathrm{X}$ & & $\mathrm{X}$ & & & Manão (2011); Maurenza et al. (2018) & & $\mathrm{X}$ & \\
\hline VU & - & - & Malpighiaceae & $\begin{array}{l}\text { Heteropterys crinigera } \\
\text { Griseb. }\end{array}$ & $\mathrm{TR}$ & & $\mathrm{X}$ & & $\mathrm{X}$ & & & Andrade (2015) & & $\mathrm{X}$ & \\
\hline VU & $\mathrm{EN}$ & $\mathrm{CR}$ & Marantaceae & $\begin{array}{l}\text { Maranta subterranea } \\
\text { J.M.A.Braga }\end{array}$ & $\mathrm{HE}$ & & $\mathrm{X}$ & & $\mathrm{X}$ & & & $\begin{array}{l}\text { A.A.M. de Barros } 5131 \text { (RFFP); A.A.M. de } \\
\text { Barros } 5206 \text { (RFFP); A.A.M. de Barros } 5226 \\
\text { (RFFP) }\end{array}$ & & $X$ & \\
\hline VU & - & - & Meliaceae & Cedrela fissilis Vell. & $\mathrm{AR}$ & & $\mathrm{X}$ & & & & $\mathrm{X}$ & $\begin{array}{l}\text { Callado et al. (2009); Maurenza et al. (2018); Oliveira } \\
\text { (2002) }\end{array}$ & & & $\mathrm{X}$ \\
\hline VU & - & - & Meliaceae & Cedrela odorata $\mathrm{L}$. & $\mathrm{AR}$ & & $\mathrm{X}$ & & & & $\mathrm{X}$ & A.A.M. de Barros 5064 (RFFP); Manão (2011) & & $\mathrm{X}$ & \\
\hline VU & VU & - & Menispermaceae & $\begin{array}{l}\text { \# Odontocarya vitis (Vell.) } \\
\text { J.M.A.Braga }\end{array}$ & $\mathrm{AR} / \mathrm{SB}$ & & & & $\mathrm{X}$ & & & Callado et al. (2009); Manão (2011) & & $\mathrm{X}$ & \\
\hline VU & $\mathrm{CR}$ & - & Monimiaceae & $\begin{array}{l}\text { \# Macrotorus utriculatus } \\
\text { (Mart.) Perkins }\end{array}$ & $\mathrm{AR} / \mathrm{SB}$ & $\mathrm{X}$ & & & $\mathrm{X}$ & & & Manão (2011) & & $\mathrm{X}$ & \\
\hline VU & - & - & Moraceae & $\begin{array}{l}\text { Ficus cyclophylla (Miq.) } \\
\text { Miq. }\end{array}$ & $\mathrm{AR}$ & & $\mathrm{X}$ & & $\mathrm{X}$ & & & B.E. Diaz 1564 (RB); Maurenza et al. (2018) & $\mathrm{X}$ & & \\
\hline VU & $\begin{array}{l}\mathrm{EN} / \\
\mathrm{VU}\end{array}$ & $\mathrm{CR}$ & Myrtaceae & $\begin{array}{l}\text { Calyptranthes fusiformis } \\
\text { M.L.Kawas. }\end{array}$ & $\mathrm{AR}$ & & $\mathrm{X}$ & & $\mathrm{X}$ & & & $\begin{array}{l}\text { A.A.M. de Barros } 1327 \text { (RFFP); A.A.M. de } \\
\text { Barros } 4797 \text { (RFFP); A.A.M. de Barros } 5122 \\
\text { (RFFP); Callado et al. (2009); Manão (2011); } \\
\text { Maurenza et al. (2018) }\end{array}$ & & $\mathrm{X}$ & $\mathrm{X}$ \\
\hline VU & - & - & Myrtaceae & $\begin{array}{l}\text { Eugenia bunchosiifolia } \\
\text { Nied. }\end{array}$ & $\mathrm{AR}$ & & $\mathrm{X}$ & & $\mathrm{X}$ & & & $\begin{array}{l}\text { F.C. Pinheiro } 748 \text { (RB); Manão (2011); Maurenza et } \\
\text { al. (2018); Oliveira (2002) }\end{array}$ & & $\mathrm{X}$ & $\mathrm{X}$ \\
\hline VU & VU & - & Myrtaceae & Eugenia disperma Vell. & AR & & $\mathrm{X}$ & & $\mathrm{X}$ & & & Maurenza et al. (2018) & & & \\
\hline VU & - & - & Myrtaceae & $\begin{array}{l}\text { Eugenia vattimoana } \\
\text { Mattos }\end{array}$ & $\mathrm{AR}$ & & $\mathrm{X}$ & & $\mathrm{X}$ & & & Oliveira (2002); Maurenza et al. (2018) & $\mathrm{X}$ & & \\
\hline
\end{tabular}




\begin{tabular}{|c|c|c|c|c|c|c|c|c|c|c|c|c|c|c|c|}
\hline $\begin{array}{l}\text { Status } \\
\text { Atual }\end{array}$ & $\begin{array}{l}\text { Status } \\
\text { LVD }\end{array}$ & $\begin{array}{l}\text { Status } \\
\text { IG }\end{array}$ & Família & Espécie & Hábito & AI & LO & $\begin{array}{l}\text { Endêmica } \\
\text { RJ }\end{array}$ & $\begin{array}{l}\text { Endêmica } \\
\text { Brasil }\end{array}$ & $\mathrm{O}$ & $\mathrm{C}$ & Referências & $\begin{array}{l}\text { PEIG } \\
\text { VC }\end{array}$ & $\begin{array}{l}\text { PEIG } \\
\text { VO }\end{array}$ & RBEPS \\
\hline VU & - & - & Myrtaceae & $\begin{array}{l}\text { Neomitranthes } \\
\text { amblymitra (Burret) } \\
\text { Mattos }\end{array}$ & $\mathrm{AR}$ & & $\mathrm{X}$ & & $\mathrm{X}$ & & & L.P.G. Rosa s.n. (HRJ 12419) & & & \\
\hline VU & VU & - & Myrtaceae & Plinia edulis (Vell.) Sobral & $\mathrm{AR}$ & & $\mathrm{X}$ & & $\mathrm{X}$ & & $\mathrm{X}$ & $\begin{array}{l}\text { I. Souza et A.C.P. Couto } 225 \text { (EFC); L.P.G. Rosa s.n. } \\
\text { (HRJ 12423); Manão (2011); Maurenza et al. (2018) }\end{array}$ & & $\mathrm{X}$ & \\
\hline VU & - & - & Orchidaceae & $\begin{array}{l}\text { If Acianthera } \\
\text { subrotundifolia (Cogn.) } \\
\text { F.Barros \& V.T.Rodrigues }\end{array}$ & $\mathrm{HE}$ & & & $\mathrm{X}$ & $\mathrm{X}$ & $\mathrm{X}$ & & M.R.A. Braga 352 (RB); Menini Neto et al. (2018) & & & \\
\hline VU & VU & $\mathrm{CR}$ & Orchidaceae & Cattleya guttata Lindl. & $\mathrm{HE}$ & & $\mathrm{X}$ & & $\mathrm{X}$ & $\mathrm{X}$ & & $\begin{array}{l}\text { A.A.M. de Barros } 4807 \text { (RFFP); Araújo \& } \\
\text { Oliveira (1988); Callado et al. (2009); Cruz \& Nunes- } \\
\text { Freitas (2017); Manão (2011); Maurenza et al. (2018) }\end{array}$ & & $\mathrm{X}$ & $\mathrm{X}$ \\
\hline VU & $\mathrm{CR}$ & - & Orchidaceae & $\begin{array}{l}\text { Grandiphyllum hians } \\
\text { (Lindl) Docha Neto }\end{array}$ & HE & & $\mathrm{X}$ & & $\mathrm{X}$ & $\mathrm{X}$ & & Cruz \& Nunes-Freitas (2017) & & & $\mathrm{X}$ \\
\hline VU & - & - & Orchidaceae & $\begin{array}{l}\text { H Stelis palmeiraensis } \\
\text { Barb.Rodr. }\end{array}$ & HE & & & $\mathrm{X}$ & $\mathrm{X}$ & & & $\begin{array}{l}\text { M.R.A. Braga } 359 \text { (RB); Menini Neto et al. } \\
\text { (2018) }\end{array}$ & & & \\
\hline VU & VU & - & Proteaceae & Roupala sculpta Sleumer & $\mathrm{AR}$ & & $\mathrm{X}$ & & $\mathrm{X}$ & & $\mathrm{X}$ & A. T. Silva s.n. (RBR 32998); Maurenza et al. (2018) & & & \\
\hline VU & - & $\mathrm{CR}$ & Rubiaceae & $\begin{array}{l}\text { Melanopsidium nigrum } \\
\text { Colla }\end{array}$ & $\mathrm{AR} / \mathrm{SB}$ & $\mathrm{X}$ & $\mathrm{X}$ & & $\mathrm{X}$ & & $\mathrm{X}$ & $\begin{array}{l}\text { A. Lobão et al. } 464 \text { (RB); L.R. Caires } 88 \text { (RFFP); L.R. } \\
\text { Caires } 105 \text { (RFFP); Callado et al. (2009); Maurenza } \\
\text { et al. (2018) }\end{array}$ & & $\mathrm{X}$ & $\mathrm{X}$ \\
\hline VU & - & - & Rubiaceae & $\begin{array}{l}\text { \# Rudgea francavillana } \\
\text { Müll.Arg. }\end{array}$ & SB & $X$ & & & $\mathrm{X}$ & & & Callado et al. (2009); Manão (2011) & & $\mathrm{X}$ & \\
\hline VU & EN & - & Rubiaceae & $\begin{array}{l}\text { Rudgea jasminoides } \\
\text { (Cham.) Müll.Arg. }\end{array}$ & $\mathrm{AR} / \mathrm{SB}$ & & $X$ & & & & & L.P.G. Rosa s.n. (HRJ 12231) & & & \\
\hline VU & VU & - & Sapindaceae & Cupania concolor Radlk. & $\mathrm{AR}$ & & & & $\mathrm{X}$ & & $\mathrm{X}$ & $\begin{array}{l}\text { D.M. Silva et al. } 96 \text { (HB); L.P.G. Rosa s.n. (HRJ } \\
\text { 12458); Callado et al. (2009); Maurenza et al. (2018) }\end{array}$ & $X$ & & \\
\hline VU & - & - & Sapindaceae & $\begin{array}{l}\text { Cupania furfuraceae } \\
\text { Radlk. }\end{array}$ & $\mathrm{AR}$ & & $\mathrm{X}$ & & $\mathrm{X}$ & & $\mathrm{X}$ & $\begin{array}{l}\text { I.E. Santo et M.F. Castilhor } 1204 \text { (HB); I.E. Santo } \\
\text { et M.F. Castilhori 1271 (HB); L.P.G. Rosa s.n. (HRJ } \\
\text { 12459); Manão (2011); Maurenza et al. (2018) }\end{array}$ & & $\mathrm{X}$ & \\
\hline NT & $\mathrm{CR}$ & EN & Annonaceae & $\begin{array}{l}\text { Xylopia brasiliensis } \\
\text { Spreng. }\end{array}$ & $\mathrm{AR}$ & & & & $\mathrm{X}$ & $\mathrm{X}$ & $\mathrm{X}$ & $\begin{array}{l}\text { A.A.M. de Barros } 5063 \text { (RFFP); A.A.M. de } \\
\text { Barros } 5366 \text { (RFFP); D.N.S. Machado } 458 \text { (RFFP); } \\
\text { L.P.G. Rosa } 2 \text { (HRJ); Oliveira (2002); Callado et al. } \\
\text { (2009); Manão (2011) }\end{array}$ & $\mathrm{X}$ & $X$ & \\
\hline
\end{tabular}


Tabela 1. Cont.

\begin{tabular}{|c|c|c|c|c|c|c|c|c|c|c|c|c|c|c|c|}
\hline $\begin{array}{l}\text { Status } \\
\text { Atual }\end{array}$ & $\begin{array}{c}\text { Status } \\
\text { LVD }\end{array}$ & $\begin{array}{c}\text { Status } \\
\text { IG }\end{array}$ & Família & Espécie & Hábito & AI & LO & $\begin{array}{l}\text { Endêmica } \\
\text { RJ }\end{array}$ & $\begin{array}{l}\text { Endêmica } \\
\text { Brasil }\end{array}$ & $\mathrm{O}$ & $\mathrm{C}$ & Referências & $\begin{array}{l}\text { PEIG } \\
\text { VC }\end{array}$ & $\begin{array}{l}\text { PEIG } \\
\text { VO }\end{array}$ & RBEPS \\
\hline NT & VU & - & Araceae & $\begin{array}{l}\text { Anthurium ianthinopodum } \\
\text { (Schott ex Engl.) Nadruz } \\
\text { \& Mayo }\end{array}$ & $\mathrm{HE}$ & & & & $\mathrm{X}$ & & & Manão (2011) & & $\mathrm{X}$ & \\
\hline NT & - & - & Araceae & $\begin{array}{l}\text { * Philodendron } \\
\text { curvilobum Schott }\end{array}$ & $\mathrm{HE}$ & & & & $\mathrm{X}$ & & & $\begin{array}{l}\text { A.C.R. Cruz } 18 \text { (RBR); Calazans (2014); Callado et } \\
\text { al. (2009) }\end{array}$ & & & $\mathrm{X}$ \\
\hline NT & - & - & Asteraceae & $\begin{array}{l}\text { Mikania rufescens Schult } \\
\text { Bip. ex Benth. }\end{array}$ & $\mathrm{HE}$ & & & & $\mathrm{X}$ & & & Andrade (2015) & & $\mathrm{X}$ & \\
\hline NT & - & - & Fabaceae & Inga sellowiana Benth. & $\mathrm{AR}$ & & & & $\mathrm{X}$ & & $\mathrm{X}$ & $\begin{array}{l}\text { D. Araujo } 6217 \text { (RB); Araújo \& Oliveira (1988); } \\
\text { Callado et al. (2009) }\end{array}$ & & & $\mathrm{X}$ \\
\hline NT & & & Fabaceae & $\begin{array}{l}\text { Tachigali denudata } \\
\text { (Vogel) Oliveira-Filho }\end{array}$ & $\mathrm{AR}$ & & & & $\mathrm{X}$ & & $\mathrm{X}$ & L.P.G. Rosa s.n. (HRJ 12325) & & & \\
\hline NT & - & - & Humiriaceae & $\begin{array}{l}\text { * Humiriastrum dentatum } \\
\text { (Casar.) Cuatrec. }\end{array}$ & $\mathrm{HE}$ & & & & $\mathrm{X}$ & & & Giordano (2014) & & & $\mathrm{X}$ \\
\hline NT & VU & - & Malpighiaceae & $\begin{array}{l}\text { Heteropterys patens } \\
\text { (Griseb.) A.Juss. }\end{array}$ & LI & & & & $\mathrm{X}$ & & & A.A.M. de Barros 5065 (RFFP) & & $X$ & \\
\hline NT & VU & EN & Marantaceae & $\begin{array}{l}\text { Goeppertia aemula } \\
\text { (Körn.) Borchs \& Suárez }\end{array}$ & $\mathrm{HE}$ & & & & $X$ & $\mathrm{X}$ & & $\begin{array}{l}\text { A.A.M. de Barros } 1441 \text { (RFFP); A.A.M. de Barros } \\
3487 \text { (RFFP) }\end{array}$ & & $\mathrm{X}$ & \\
\hline NT & $\begin{array}{l}\mathrm{RE} / \\
\mathrm{VU}\end{array}$ & - & Orchidaceae & $\begin{array}{l}\text { Epidendrum hololeucum } \\
\text { Barb.Rodr. }\end{array}$ & $\mathrm{HE}$ & & & & $\mathrm{X}$ & $X$ & & M.R.A Braga et R. Motta 368 (RB) & & & \\
\hline NT & $\begin{array}{l}\text { EX/ } \\
\text { VU }\end{array}$ & $\mathrm{CR}$ & Piperaceae & Piper scutifolium Yunck. & $\mathrm{SB} / \mathrm{LI}$ & & & & $\mathrm{X}$ & & & $\begin{array}{l}\text { G.A. de Queiroz } 140 \text { (RFFP); T.S. Mendes } 103 \\
\text { (RFFP) }\end{array}$ & & $X$ & \\
\hline NT & EN & - & Rubiaceae & $\begin{array}{l}\text { Faramea coerulea (Nees } \\
\text { \& Mart.) DC. }\end{array}$ & SB & $\mathrm{X}$ & & & $\mathrm{X}$ & & & A.A.M. de Barros 4788 (RFFP) & & $\mathrm{X}$ & \\
\hline NT & VU & - & Rutaceae & $\begin{array}{l}\text { Pilocarpus giganteous } \\
\text { Engl. }\end{array}$ & $\mathrm{AR}$ & & & & $\mathrm{X}$ & & & L.R. Caires 83 (RFFP); Manão (2011) & & $\mathrm{X}$ & \\
\hline NT & - & - & Sapotaceae & $\begin{array}{l}\text { Micropholis compta Pierre } \\
\text { in Urb. }\end{array}$ & $\mathrm{AR}$ & & & & $\mathrm{X}$ & & & sem coletor (HRJ 11717) & & & \\
\hline NT & - & - & Urticaceae & $\begin{array}{l}\text { Coussapoa curranii } \\
\text { S.F.Blake }\end{array}$ & $\mathrm{AR}$ & & & & $\mathrm{X}$ & & & M.D.M. Vianna Filho 3001 (HRJ) & $\mathrm{X}$ & & \\
\hline
\end{tabular}


As espécies Anthurium luschnathianum, Cattleya guttata Lindl. (Orchidaceae), Euterpe edulis, Hippeastrum striatum (Lam.) Moore (Amaryllidaceae), Maranta subterranea J.M.A.Braga (Marantaceae), Rudgea macrophylla e Rhipsalis oblonga Loefgr. (Cactaceae), ocorrem principalmente nas trilhas coincidentemente mais visitadas pelos turistas, principalmente na alta temporada.

As famílias com maior riqueza de espécies foram Bromeliaceae (9 ssp.), Myrtaceae (7 ssp.), Orchidaceae (7 spp.), Rubiaceae (6 spp.), Melastomataceae (5 spp.) e Araceae (4 spp.), correspondendo a cerca de $46 \%$ das espécies levantadas e a maioria com potencial ornamental (Tabs. 1, 2).

Entre as espécies analisadas em estado de ameaça na Ilha Grande, 17 foram apontadas com valor ornamental e 16 com interesse econômico, somando um total de 29 espécies com algum valor associado (Tabs. 1, 3). No entanto, de todas as espécies avaliadas, apenas $56 \%$ estão protegidas do corte e ou exploração por Lei, de acordo com a Lista Oficial de Espécies da Flora Ameaçadas de
Extinção, publicada pela Portaria MMA n ${ }^{\circ} 443$, de 17 de dezembro de 2014 (MMA 2014).

Somando-se a listagem (Tabs. 1, 2), foram verificadas 18 espécies ocorrentes na Ilha Grande cujas informações disponíveis, como distribuição geográfica, tamanho populacional ou mesmo ameaçadas, não são suficientes ou adequadas para uma avaliação de seu risco de extinção, sendo consideradas como espécies com Dados Insuficientes (DD) (Tab. 4). Nenhuma das espécies classificadas como DD são endêmicas do Rio de Janeiro, e cerca de $61 \%$ são endêmicas do Brasil. Assim como as espécies consideradas como Quase Ameaçadas (NT), estas não foram incluídas na Lista Oficial de Espécies da Flora Ameaçadas de Extinção, publicada pela Portaria MMA nº43, de 17 de dezembro de 2014. Apenas Rhipsalis crispata (Haw.) Pfeiff. (Cactaceae) e Warczewiczella wailesiana (Lindl.) Rchb.f. ex E.Morren (Orchidaceae) são legalmente protegidas de acordo com a convenção sobre o comércio internacional de espécies selvagens da flora e fauna (UNEP-WCMC 2019).

Tabela 2. Distribuição geográfica e tipo de vegetação das espécies da flora presentes na Lista Vermelha de espécies ameaçadas da Ilha Grande, Angra dos Reis, Rio de Janeiro, Brasil. Legenda: Distribuição Geográfica: X = Informação Insuficiente; Tipo de Vegetação: AA = Área Antrópica, CA = Campos de Altitude, $\mathrm{CAA}=$ Caatinga, $\mathrm{CEL}=$ Cerrado (latu sensu), $\mathrm{CR}=$ Campo Rupestre, $\mathrm{FE}=$ Floresta Estacional, $\mathrm{FED}=$ Floresta Estacional Decidual, FEP = Floresta Estacional Perenifólia, FES = Floresta Estacional Semidecidual, $\mathrm{FC}=$ Floresta Ciliar, FOD = Floresta Ombrófila Densa, $\mathrm{RE}=$ Restinga, $\mathrm{FOM}=$ Floresta Ombrófila Mista, FTF $=$ Floresta de Terra Firme, FV = Floresta de Várzea, GA = Galeria, MAN = Manguezal, VAR = Vegetação sobre Afloramento Rochoso; Origem: MA = Mata Atlântica, $\mathrm{CE}=$ Cerrado, $\mathrm{AM}=$ Amazônia, CA = Caatinga.

\begin{tabular}{|c|c|c|c|c|c|}
\hline Status & Família & Espécie & $\begin{array}{c}\text { Distribuição } \\
\text { Geográfica Brasil }\end{array}$ & Tipo de vegetação & Origem \\
\hline $\mathrm{CR}$ & Bignoniaceae & $\begin{array}{l}\text { Adenocalymma ubatubense Assis } \\
\text { \& Semir }\end{array}$ & $\mathrm{RJ} / \mathrm{SP}$ & FOD & MA \\
\hline $\mathrm{CR}$ & Bromeliaceae & Vriesea rubyae E.Pereira & RJ & $\mathrm{FO}$ & MA \\
\hline $\mathrm{CR}$ & Cyperaceae & $\begin{array}{l}\text { Pleurostachys pilulifera Longhi- } \\
\text { Wagner, Baldini \& A.C.Araújo }\end{array}$ & $\mathrm{RJ} / \mathrm{SP}$ & $\mathrm{FO}$ & MA \\
\hline $\mathrm{CR}$ & Melastomataceae & Bertolonia valenteana Baumgratz & RJ & $\mathrm{FO}$ & MA \\
\hline CR & Pteridaceae & Cheilanthes incisa Kunze ex Mett. & RJ & $\mathrm{FO}$ & MA \\
\hline $\mathrm{EN}$ & Amaryllidaceae & $\begin{array}{l}\text { Hippeastrum striatum (Lam.) } \\
\text { Moore }\end{array}$ & $\begin{array}{l}\mathrm{BA} / \mathrm{SE} / \mathrm{RJ} / \mathrm{SP} / \mathrm{MG} / \\
\mathrm{ES} / \mathrm{PR} / \mathrm{RS} / \mathrm{SC}\end{array}$ & $\mathrm{FES} / \mathrm{FO} / \mathrm{RE}$ & MA \\
\hline EN & Araceae & Anthurium luschnathianum Kunth & $\mathrm{RJ}$ & $\mathrm{FO}$ & MA \\
\hline $\mathrm{EN}$ & Begoniaceae & Begonia undulata Schott & $\mathrm{RJ} / \mathrm{SP}$ & $\mathrm{RE}$ & MA \\
\hline $\mathrm{EN}$ & Bignoniaceae & Tabebuia cassinoides (Lam.) DC. & $\mathrm{ES} / \mathrm{MG} / \mathrm{RJ} / \mathrm{SP}$ & $\mathrm{FO}$ & MA \\
\hline EN & Bromeliaceae & Neoregelia hoehneana L.B.Sm. & $\mathrm{RJ} / \mathrm{SP}$ & FO & MA \\
\hline $\mathrm{EN}$ & Bromeliaceae & Wittrockia superba Lindm. & $\mathrm{RJ} / \mathrm{SP} / \mathrm{PR} / \mathrm{SC}$ & $\mathrm{FO}$ & MA \\
\hline $\mathrm{EN}$ & Chrysobalanaceae & Couepia schottii Fritsch & $\mathrm{ES} / \mathrm{RJ} / \mathrm{BA}$ & $\mathrm{RE}$ & MA \\
\hline $\mathrm{EN}$ & Elaeocarpaceae & $\begin{array}{l}\text { Sloanea obtusifolia (Moric.) } \\
\text { Schum. }\end{array}$ & $\begin{array}{l}\mathrm{BA} / \mathrm{PE} / \mathrm{ES} / \mathrm{MG} / \\
\mathrm{RJ} / \mathrm{SP}\end{array}$ & $\mathrm{FC} / \mathrm{GA} / \mathrm{FO}$ & MA \\
\hline $\mathrm{EN}$ & Lauraceae & Ocotea odorifera (Vell.) Rowher & $\begin{array}{l}\mathrm{MG} / \mathrm{RJ} / \mathrm{SP} / \mathrm{PR} / \mathrm{RS} / \\
\mathrm{SC}\end{array}$ & $\mathrm{FED} / \mathrm{FO}$ & $\mathrm{CE} / \mathrm{MA}$ \\
\hline $\mathrm{EN}$ & Lecythidaceae & Couratari pyramidata (Vell.) Kunth & RJ & FO & MA \\
\hline $\mathrm{EN}$ & Marantaceae & Ischnosiphon ovatus Körn & $\begin{array}{l}\mathrm{BA} / \mathrm{RJ} / \mathrm{SP} / \mathrm{MG} / \mathrm{ES} / \\
\mathrm{PR} / \mathrm{SC}\end{array}$ & $\mathrm{FES} / \mathrm{FO} / \mathrm{RE} / \mathrm{VAR}$ & MA \\
\hline $\mathrm{EN}$ & Melastomataceae & Meriania glazioviana Cogn. & RJ & FO & MA \\
\hline $\mathrm{EN}$ & Melastomataceae & Meriania longipes Triana & RJ & FO & MA \\
\hline $\mathrm{EN}$ & Melastomataceae & Miconia gigantea Cogn. & RJ & FO & MA \\
\hline $\mathrm{EN}$ & Melastomataceae & Pleroma thereminiana (DC.) Triana & RJ & $\mathrm{FO}$ & MA \\
\hline
\end{tabular}


Tabela 2. Cont.

\begin{tabular}{|c|c|c|c|c|c|}
\hline Status & Família & Espécie & $\begin{array}{c}\text { Distribuição } \\
\text { Geográfica Brasil }\end{array}$ & Tipo de vegetação & Origem \\
\hline $\mathrm{EN}$ & Monimiaceae & $\begin{array}{l}\text { Mollinedia glabra (Sprengel) } \\
\text { Perkins }\end{array}$ & $\mathrm{BA} / \mathrm{ES} / \mathrm{RJ} / \mathrm{SP} / \mathrm{MG}$ & $\mathrm{FO} / \mathrm{RE}$ & MA \\
\hline $\mathrm{EN}$ & Myristicaceae & $\begin{array}{l}\text { Virola bicuhyba (Schott ex Spreng.) } \\
\text { Warb. }\end{array}$ & $\begin{array}{l}\mathrm{BA} / \mathrm{ES} / \mathrm{MG} / \mathrm{RJ} / \mathrm{SP} / \\
\mathrm{PR} / \mathrm{RS} / \mathrm{SC}\end{array}$ & $\mathrm{FC} / \mathrm{FO}$ & MA \\
\hline $\mathrm{EN}$ & Myrtaceae & Eugenia malacantha D.Legrand & $\mathrm{RJ} / \mathrm{SP} / \mathrm{PR} / \mathrm{SC}$ & $\mathrm{FES} / \mathrm{FO}$ & MA \\
\hline $\mathrm{EN}$ & Orchidaceae & Octomeria alexandri Schltr. & $\begin{array}{l}\mathrm{BA} / \mathrm{PE} / \mathrm{RJ} / \mathrm{SP} / \mathrm{ES} / \\
\mathrm{RS} / \mathrm{SC}\end{array}$ & $\mathrm{CR} / \mathrm{FES} / \mathrm{FO} / \mathrm{VAR}$ & $\mathrm{CE} / \mathrm{MA}$ \\
\hline $\mathrm{EN}$ & Orchidaceae & Rauhiella silvana Toscano & $\mathrm{BA} / \mathrm{ES} / \mathrm{RJ}$ & FO & MA \\
\hline $\mathrm{EN}$ & Rubiaceae & Rudgea interrupta Benth. & $\mathrm{BA} / \mathrm{ES} / \mathrm{RJ}$ & FO & MA \\
\hline $\mathrm{EN}$ & Rubiaceae & Rudgea macrophylla Benth. & RJ & FO & MA \\
\hline $\mathrm{EN}$ & Sapotaceae & Pradosia kuhlmannii Toledo & $\mathrm{BA} / \mathrm{PE} / \mathrm{ES} / \mathrm{RJ}$ & FO & MA \\
\hline $\mathrm{EN}$ & Smilacaceae & Smilax spicta Vell. & $\mathrm{ES} / \mathrm{RJ} / \mathrm{SP}$ & $\mathrm{FO}$ & MA \\
\hline VU & Araceae & $\begin{array}{l}\text { Monstera praetermissa E.G.Gonç. } \\
\text { \& Temponi }\end{array}$ & $\begin{array}{l}\mathrm{AC} / \mathrm{PA} / \mathrm{RO} / \mathrm{BA} / \mathrm{CE} / \\
\mathrm{PE} / \mathrm{GO} / \mathrm{MT} / \\
\mathrm{ES} / \mathrm{RJ} / \mathrm{MG} / \mathrm{SP} / \mathrm{PR}\end{array}$ & $\mathrm{FES} / \mathrm{FO}$ & $\mathrm{AM} / \mathrm{MA}$ \\
\hline VU & Arecaceae & Euterpe edulis Mart. & $\begin{array}{l}\mathrm{AL} / \mathrm{BA} / \mathrm{PA} / \mathrm{PE} / \mathrm{RN} / \\
\mathrm{SE} / \mathrm{DF} / \mathrm{GO} / \mathrm{ES} / \mathrm{MG} / \\
\mathrm{RJ} / \mathrm{SP} / \mathrm{PR} / \mathrm{RS} / \mathrm{SC}\end{array}$ & $\mathrm{FC} / \mathrm{GA} / \mathrm{FO}$ & $\mathrm{CE} / \mathrm{MA}$ \\
\hline VU & Aristochiaceae & Aristolochia odora Steud. & $\mathrm{BA} / \mathrm{ES} / \mathrm{SP} / \mathrm{MG} / \mathrm{RJ}$ & $\mathrm{AA} / \mathrm{FES} / \mathrm{FO}$ & MA \\
\hline VU & Asteraceae & Mikania argyreiae DC. & $\mathrm{BA} / \mathrm{MG} / \mathrm{RJ} / \mathrm{SP} / \mathrm{PR}$ & $\mathrm{AA} / \mathrm{CA} / \mathrm{FO}$ & $\mathrm{CE} / \mathrm{MA}$ \\
\hline VU & Begoniaceae & $\begin{array}{l}\text { Begonia curtii L.B.Sm. \& } \\
\text { B.G.Schub }\end{array}$ & $\mathrm{RJ} / \mathrm{ES} / \mathrm{MG}$ & FO & MA \\
\hline VU & Bromeliaceae & Aechmea gracilis Lindm. & $\mathrm{RJ} / \mathrm{SP} / \mathrm{SC} / \mathrm{PR}$ & $\mathrm{FO}$ & MA \\
\hline VU & Bromeliaceae & $\begin{array}{l}\text { Neoregelia cruenta (R.Graham) } \\
\text { L.B.Sm. }\end{array}$ & $\mathrm{BA} / \mathrm{ES} / \mathrm{RJ} / \mathrm{SP}$ & MAN/RE/VAR & MA \\
\hline VU & Bromeliaceae & Nidularium serratum Leme & $\mathrm{ES} / \mathrm{RJ}$ & $\mathrm{FO}$ & MA \\
\hline VU & Bromeliaceae & Vriesea bituminosa Wawra & $\mathrm{BA} / \mathrm{ES} / \mathrm{RJ} / \mathrm{SP} / \mathrm{MG}$ & FO & MA \\
\hline VU & Bromeliaceae & Vriesea neoglutinosa $\mathrm{Mez}$ & $\mathrm{BA} / \mathrm{ES} / \mathrm{RJ} / \mathrm{SP} / \mathrm{PR} / \mathrm{SC}$ & RE/VAR & MA \\
\hline VU & Bromeliaceae & Vriesea rodigasiana E.Morren & $\begin{array}{l}\mathrm{BA} / \mathrm{CE} / \mathrm{PE} / \mathrm{RJ} / \mathrm{SP} / \\
\mathrm{ES} / \mathrm{PR} / \mathrm{SC} / \mathrm{RS}\end{array}$ & FES & MA \\
\hline VU & Cactaceae & Rhipsalis oblonga Loefgr. & $\mathrm{BA} / \mathrm{ES} / \mathrm{MG} / \mathrm{RJ} / \mathrm{SP}$ & $\mathrm{FOM} / \mathrm{FC} / \mathrm{GA}$ & MA \\
\hline VU & Euphorbiaceae & Euphorbia insulana Vell. & $\begin{array}{l}\mathrm{AL} / \mathrm{BA} / \mathrm{CE} / \mathrm{PB} / \mathrm{PE} / \\
\mathrm{RN} / \mathrm{SE} / \mathrm{GO} / \mathrm{MT} / \mathrm{ES} / \\
\mathrm{RJ} / \mathrm{MG} / \mathrm{SP} / \mathrm{PR} / \mathrm{SC}\end{array}$ & $\mathrm{RE}$ & MA \\
\hline VU & Fabaceae & Inga platyptera Benth. & $\mathrm{ES} / \mathrm{MG} / \mathrm{RJ}$ & $\mathrm{FES} / \mathrm{FO}$ & MA \\
\hline VU & Gesnesriaceae & $\begin{array}{l}\text { Codonanthe carnosa (Gardner) } \\
\text { Hanst. }\end{array}$ & $\mathrm{ES} / \mathrm{MG} / \mathrm{RJ} / \mathrm{SP}$ & $\mathrm{FC} / \mathrm{GA} / \mathrm{FO}$ & MA \\
\hline VU & Heliconiaceae & Heliconia farinosa Raddi & $\mathrm{ES} / \mathrm{RJ} / \mathrm{SP} / \mathrm{PR} / \mathrm{RS} / \mathrm{SC}$ & FO & MA \\
\hline VU & Lauraceae & $\begin{array}{l}\text { Urbanodendron bahiense (Meisn.) } \\
\text { Rohwer }\end{array}$ & $\mathrm{BA} / \mathrm{RJ} / \mathrm{SP}$ & $\mathrm{FO}$ & MA \\
\hline VU & Malpighiaceae & Heteropterys crinigera Griseb. & $\mathrm{RJ} / \mathrm{SP}$ & FO & MA \\
\hline VU & Marantaceae & Maranta subterranea J.M.A. Braga & $\mathrm{BA} / \mathrm{ES} / \mathrm{RJ}$ & $\mathrm{FES} / \mathrm{FO}$ & MA \\
\hline VU & Meliaceae & Cedrela fissilis Vell. & $\begin{array}{l}\mathrm{AL} / \mathrm{AP} / \mathrm{AM} / \mathrm{BA} / \mathrm{CE} / \\
\mathrm{DF} / \mathrm{ES} / \mathrm{GO} / \mathrm{MA} / \mathrm{MT} / \\
\mathrm{MS} / \mathrm{MG} / \mathrm{PA} / \mathrm{PB} / \mathrm{PR} / \\
\mathrm{PE} / \mathrm{RJ} / \mathrm{RO} / \mathrm{SC} / \mathrm{SP} / \\
\mathrm{SE} / \mathrm{TO} / \mathrm{PI} / \mathrm{RS}\end{array}$ & $\begin{array}{l}\mathrm{CEL} / \mathrm{FED} / \mathrm{FEP} / \\
\mathrm{FES} / \mathrm{FO} / \mathrm{FTF}\end{array}$ & $\mathrm{AM} / \mathrm{CE} / \mathrm{MA}$ \\
\hline VU & Meliaceae & Cedrela odorata L. & $\begin{array}{l}\mathrm{AL} / \mathrm{AP} / \mathrm{AM} / \mathrm{BA} / \mathrm{CE} / \\
\mathrm{DF} / \mathrm{ES} / \mathrm{GO} / \mathrm{MA} / \mathrm{MT} / \\
\mathrm{MS} / \mathrm{MG} / \mathrm{PA} / \mathrm{PB} / \mathrm{PR} / \\
\mathrm{PE} / \mathrm{RJ} / \mathrm{RO} / \mathrm{SC} / \mathrm{SP} / \mathrm{SE}\end{array}$ & $\begin{array}{l}\mathrm{CAA} / \mathrm{CEL} / \mathrm{FC} / \mathrm{GA} / \\
\mathrm{FV} / \mathrm{FED} / \mathrm{FEP} / \mathrm{FES} / \\
\mathrm{FO}\end{array}$ & $\mathrm{AM} / \mathrm{CA} / \mathrm{CE} \mathrm{MA}$ \\
\hline VU & Menispermaceae & $\begin{array}{l}\text { Odontocarya vitis (Vell.) } \\
\text { J.M.A.Braga }\end{array}$ & $\mathrm{BA} / \mathrm{ES} / \mathrm{RJ} / \mathrm{SP}$ & FED/FO/RE/VAR & MA \\
\hline
\end{tabular}


Tabela 2. Cont.

\begin{tabular}{|c|c|c|c|c|c|}
\hline Status & Família & Espécie & $\begin{array}{l}\text { Distribuição } \\
\text { Geográfica Brasil }\end{array}$ & Tipo de vegetação & Origem \\
\hline VU & Monimiaceae & $\begin{array}{l}\text { Macrotorus utriculatus (Mart.) } \\
\text { Perkins }\end{array}$ & $\mathrm{ES} / \mathrm{RJ} / \mathrm{SP}$ & FO & MA \\
\hline VU & Moraceae & Ficus cyclophylla (Miq.) Miq. & $\begin{array}{l}\mathrm{PA} / \mathrm{SE} / \mathrm{BA} / \mathrm{MG} / \mathrm{SP} / \\
\mathrm{ES} / \mathrm{RJ}\end{array}$ & $\mathrm{FO} / \mathrm{RE}$ & MA \\
\hline VU & Myrtaceae & $\begin{array}{l}\text { Calyptranthes } \\
\text { fusiformis M.L.Kawas. }\end{array}$ & $\mathrm{RJ} / \mathrm{SP}$ & $\mathrm{FO}$ & MA \\
\hline VU & Myrtaceae & Eugenia bunchosiifolia Nied. & $\mathrm{RJ} / \mathrm{SP} / \mathrm{PR}$ & FO & MA \\
\hline VU & Myrtaceae & Eugenia disperma Vell. & $\mathrm{RJ} / \mathrm{SP}$ & FO & MA \\
\hline VU & Myrtaceae & Eugenia vattimoana Mattos & $\mathrm{MG} / \mathrm{RJ}$ & $\mathrm{FES} / \mathrm{FO} / \mathrm{FOM} / \mathrm{RE}$ & MA \\
\hline VU & Myrtaceae & $\begin{array}{l}\text { Neomitranthes amblymitra (Burret) } \\
\text { Mattos }\end{array}$ & $\mathrm{MG} / \mathrm{RJ} / \mathrm{SP}$ & FES/FO & MA \\
\hline VU & Myrtaceae & Plinia edulis (Vell.) Sobral & $\begin{array}{l}\mathrm{TO} / \mathrm{BA} / \mathrm{RN} / \mathrm{ES} / \mathrm{RJ} / \\
\mathrm{SP} / \mathrm{PR} / \mathrm{SC} / \mathrm{RS}\end{array}$ & FO & MA \\
\hline VU & Orchidaceae & $\begin{array}{l}\text { Acianthera subrotundifolia (Cogn.) } \\
\text { F.Barros \& V.T.Rodrigues }\end{array}$ & RJ & FO & MA \\
\hline VU & Orchidaceae & Cattleya guttata Lindl. & $\begin{array}{l}\mathrm{BA} / \mathrm{PE} / \mathrm{RJ} / \mathrm{ES} / \mathrm{MG} / \\
\mathrm{SP} / \mathrm{PR} / \mathrm{SC}\end{array}$ & FO & MA \\
\hline VU & Orchidaceae & $\begin{array}{l}\text { Grandiphyllum hians (Lindl.) } \\
\text { Docha Neto }\end{array}$ & $\begin{array}{l}\mathrm{ES} / \mathrm{MG} / \mathrm{RJ} / \mathrm{SP} / \mathrm{PR} / \\
\mathrm{SC} / \mathrm{RS}\end{array}$ & FES/FO & MA \\
\hline VU & Orchidaceae & H Stelis palmeiraensis Barb.Rodr. & RJ & FO & MA \\
\hline VU & Proteaceae & Roupala sculpta Sleumer & $\mathrm{RJ} / \mathrm{SP}$ & FO & MA \\
\hline VU & Rubiaceae & Melanopsidium nigrum Colla & $\mathrm{BA} / \mathrm{ES} / \mathrm{RJ} / \mathrm{MG}$ & $\mathrm{CEL} / \mathrm{RE}$ & $\mathrm{CE} / \mathrm{MA}$ \\
\hline VU & Rubiaceae & Rudgea francavillana Müll.Arg. & $\mathrm{MG} / \mathrm{RJ}$ & FES/FO & MA \\
\hline VU & Rubiaceae & $\begin{array}{l}\text { Rudgea jasminoides (Cham.) } \\
\text { Müll. Arg. }\end{array}$ & $\begin{array}{l}\mathrm{ES} / \mathrm{MG} / \mathrm{RJ} / \mathrm{SP} / \mathrm{PR} / \\
\mathrm{SC}\end{array}$ & $\begin{array}{l}\mathrm{FC} / \mathrm{FES} / \mathrm{FO} / \mathrm{FOM} / \\
\mathrm{RE}\end{array}$ & $\mathrm{CE} / \mathrm{MA}$ \\
\hline VU & Sapindaceae & Cupania concolor Radlk. & $\mathrm{RJ} / \mathrm{SP} / \mathrm{MG}$ & FO & MA \\
\hline VU & Sapindaceae & Cupania furfuraceae Radlk. & $\mathrm{BA} / \mathrm{ES} / \mathrm{RJ} / \mathrm{MG}$ & FO & MA \\
\hline NT & Annonaceae & Xylopia brasiliensis Spreng. & $\mathrm{MG} / \mathrm{RJ} / \mathrm{SP} / \mathrm{PR} / \mathrm{SC}$ & FES/FO & MA \\
\hline NT & Araceae & $\begin{array}{l}\text { Anthurium ianthinopodum (Schott } \\
\text { ex Engl.) Nadruz \& Mayo }\end{array}$ & $\mathrm{BA} / \mathrm{ES}$ & FO & MA \\
\hline NT & Araceae & Philodendron curvilobum Schott & $\mathrm{MG} / \mathrm{RJ} / \mathrm{SP} / \mathrm{PR}$ & $\mathrm{FO} / \mathrm{RE}$ & MA \\
\hline NT & Asteraceae & $\begin{array}{l}\text { Mikania rufescens Schult Bip. ex } \\
\text { Benth. }\end{array}$ & $\begin{array}{l}\mathrm{BA} / \mathrm{MG} / \mathrm{RJ} / \mathrm{SP} / \mathrm{PR} / \\
\mathrm{SC} / \mathrm{RS}\end{array}$ & $\mathrm{FO} / \mathrm{RE}$ & MA \\
\hline NT & Fabaceae & Inga sellowiana Benth. & $\mathrm{RJ} / \mathrm{SP} / \mathrm{PR} / \mathrm{SC}$ & $\mathrm{FO} / \mathrm{FOM} / \mathrm{RE}$ & MA \\
\hline NT & Fabaceae & $\begin{array}{l}\text { Tachigali denudata (Vogel) } \\
\text { Oliveira-Filho }\end{array}$ & $\mathrm{ES} / \mathrm{RJ} / \mathrm{SP} / \mathrm{PR} / \mathrm{SC}$ & $\mathrm{FC} / \mathrm{FO}$ & MA \\
\hline NT & Humiriaceae & $\begin{array}{l}\text { Humiriastrum dentatum (Casar.) } \\
\text { Cuatrec. }\end{array}$ & $\mathrm{RJ} / \mathrm{SP}$ & $\mathrm{RE}$ & MA \\
\hline NT & Malpighiaceae & $\begin{array}{l}\text { Heteropterys patens (Griseb.) } \\
\text { A.Juss. }\end{array}$ & $\mathrm{RJ} / \mathrm{SP}$ & FES/FO & MA \\
\hline NT & Marantaceae & $\begin{array}{l}\text { Goeppertia aemula (Körn.) Borchs } \\
\text { \& Suárez }\end{array}$ & $\begin{array}{l}\mathrm{ES} / \mathrm{MG} / \mathrm{RJ} / \mathrm{SP} / \mathrm{PR} / \\
\mathrm{SC}\end{array}$ & $\mathrm{FO} / \mathrm{FES}$ & MA \\
\hline NT & Orchidaceae & Epidendrum hololeucum Barb.Rodr. & $\mathrm{RJ} / \mathrm{ES} / \mathrm{SP}$ & FO & MA \\
\hline NT & Piperaceae & Piper scutifolium Yunck. & $\mathrm{RJ} / \mathrm{ES} / \mathrm{SP} / \mathrm{MG}$ & $\mathrm{FO}$ & MA \\
\hline NT & Rubiaceae & $\begin{array}{l}\text { Faramea coerulea (Nees \& Mart.) } \\
\text { DC. }\end{array}$ & $\mathrm{AL} / \mathrm{BA}$ & $\mathrm{FO}$ & MA \\
\hline NT & Rutaceae & Pilocarpus giganteous Engl. & $\mathrm{BA} / \mathrm{ES} / \mathrm{RJ} / \mathrm{SP} / \mathrm{MG}$ & $\mathrm{FES} / \mathrm{FO} / \mathrm{RE}$ & MA \\
\hline NT & Sapotaceae & Micropholis compta Pierre in Urb. & $\begin{array}{l}\mathrm{BA} / \mathrm{PE} / \mathrm{ES} / \mathrm{MG} / \\
\mathrm{RJ} / \mathrm{SP}\end{array}$ & FEP/FES/FO & MA \\
\hline NT & Urticaceae & Coussapoa curranii S.F.Blake & $\mathrm{BA} / \mathrm{ES} / \mathrm{MG} / \mathrm{RJ}$ & FES/FO & $\mathrm{CE} / \mathrm{MA}$ \\
\hline
\end{tabular}




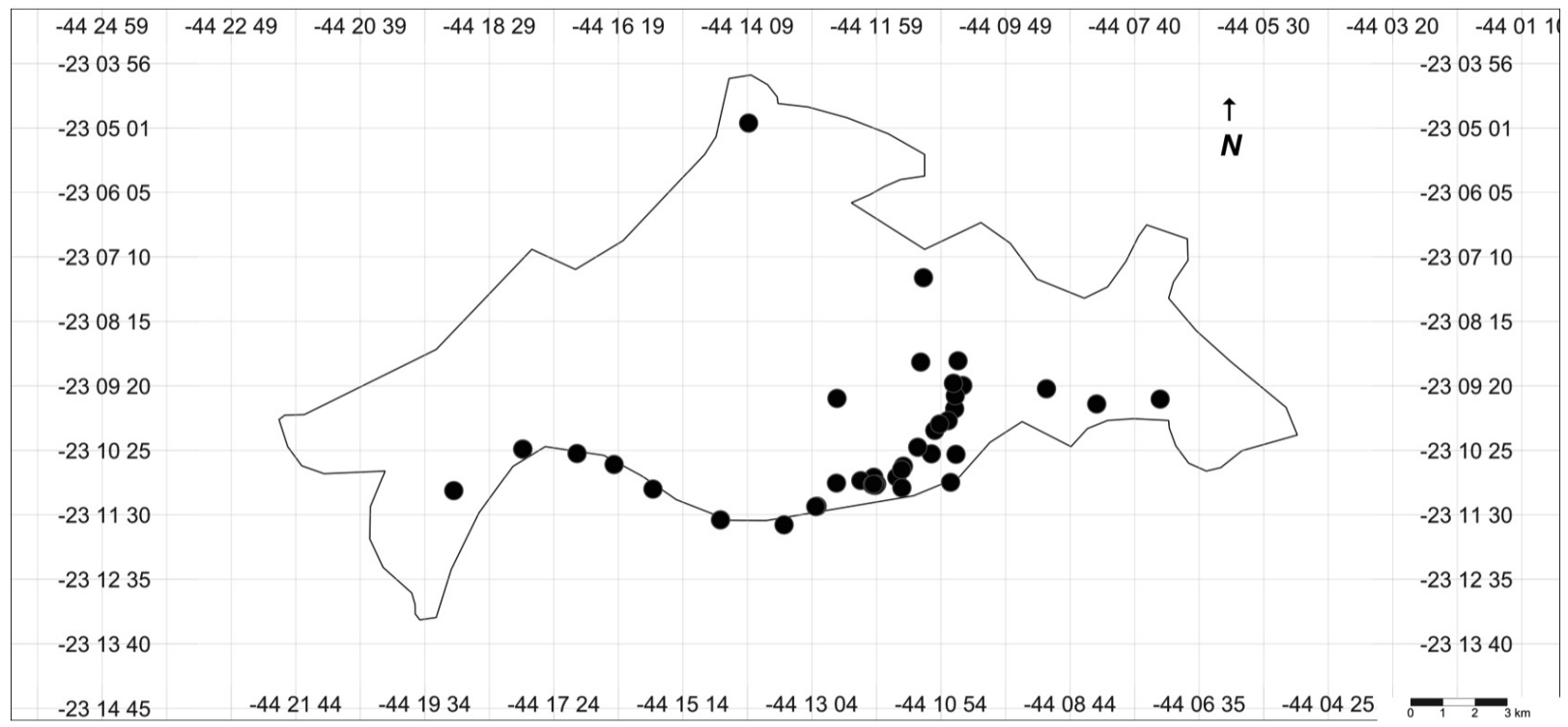

Figura 2. Distribuição da flora em estado de ameaça na Ilha Grande, Angra dos Reis, Rio de Janeiro.

Tabela 3. Uso comercial das espécies da flora presentes na Lista Vermelha de espécies ameaçadas da Ilha Grande, Angra dos Reis, Rio de Janeiro, Brasil.

\begin{tabular}{|c|c|c|}
\hline Família & Espécie & Uso comercial \\
\hline Amaryllidaceae & $\begin{array}{l}\text { Hippeastrum striatum } \\
\text { (Lam.) Moore }\end{array}$ & $\begin{array}{l}\text { Uso farmacológico (Martinelli \& Moraes 2013) e apresenta valor ornamental no mercado } \\
\text { horticultor (CNCFlora 2012). }\end{array}$ \\
\hline Annonaceae & Xylopia brasiliensis Spreng. & $\begin{array}{l}\text { Ornamental no paisagismo e arborização urbana, sua madeira é empregada na construção } \\
\text { civil, como tabuado, caibros, vigas e para confecção de mastros e caixotaria (Lorenzi 2002a). }\end{array}$ \\
\hline Arecaceae & Euterpe edulis Mart. & $\begin{array}{l}\text { Sofre extensa exploração para retirada do palmito juçara (Martinelli \& Moraes } 2013 \text { ), } \\
\text { atualmente é utilizada para a produção do açaí (Bourscheid et al. 2011) e no paisagismo } \\
\text { (Lorenzi } 2010 \text { ). }\end{array}$ \\
\hline Aristochiaceae & Aristolochia odora Steud. & Propriedades terapêuticas e medicinais (Capellari Jr. 2002). \\
\hline Elaeocarpaceae & $\begin{array}{l}\text { Sloanea obtusifolia (Moric.) } \\
\text { Schum. }\end{array}$ & $\begin{array}{l}\text { Utilizada para fins artesanais, alimentícios e na produção de combustível (Costa et al. 2006), } \\
\text { além de ser usada em construções domésticas e pesqueiras (CNCFlora 2012). }\end{array}$ \\
\hline Fabaceae & Inga sellowiana Benth. & Uso de sua madeira para lenha (CNCFlora 2012). \\
\hline Fabaceae & $\begin{array}{l}\text { Tachigali denudata (Vogel) } \\
\text { Oliveira-Filho }\end{array}$ & $\begin{array}{l}\text { Uso da madeira para fabricação de móveis, lâminas decorativas para rodapés, molduras, } \\
\text { caixas, e contrução civil, pois a madeira é resistente, além da árvore ser empregada no } \\
\text { paisagismo urbano por favorecer boa sombra, e utilizadas para reflorestamento em áreas } \\
\text { degradadas (Lorenzi 2002a). }\end{array}$ \\
\hline Lauraceae & $\begin{array}{l}\text { Ocotea odorifera (Vell.) } \\
\text { Rowher }\end{array}$ & $\begin{array}{l}\text { Uso da madeira para fabricação de móveis, lâminas decorativas para rodapés, molduras, } \\
\text { caixas, e contrução civil, pois a madeira é resistente, além da árvore ser empregada no } \\
\text { paisagismo urbano por favorecer boa sombra (Lorenzi 2002a). }\end{array}$ \\
\hline Lecythidaceae & $\begin{array}{l}\text { Couratari pyramidata } \\
\text { (Vell.) Kunth }\end{array}$ & Uso madeireiro (CNCFlora 2012). \\
\hline Meliaceae & Cedrela fissilis Vell. & $\begin{array}{l}\text { Madeira com óleo essencial que a protege contra ataques de cupins, e a casca é usada para } \\
\text { fins medicinais (Grings \& Brack 2011). }\end{array}$ \\
\hline Meliaceae & Cedrela odorata $\mathrm{L}$. & $\begin{array}{l}\text { Madeiras de maior valor comercial no mundo e é amplamente explorada, pois é } \\
\text { moderadamente resistente ao ataque de pragas, sendo usada para a fabricação de móveis, } \\
\text { laminados, compensados e tabuados em geral (Lorenzi 2002b). }\end{array}$ \\
\hline Myristicaceae & $\begin{array}{l}\text { Virola bicuhyba (Schott ex } \\
\text { Spreng.) Warb. }\end{array}$ & $\begin{array}{l}\text { Uso da madeira na construção civil, carpintaria e marcenaria, a árvore apresenta } \\
\text { características ornamentais, e por seus frutos serem procurados pelos animais silvestres, deve } \\
\text { ser utilizada em reflorestamentos, para recomposição de áreas degradadas (Lorenzi 2002a). }\end{array}$ \\
\hline Myrtaceae & Plinia edulis (Vell.) Sobral & Consumo in natura de seus frutos (CNCFlora 2012). \\
\hline Proteaceae & Roupala sculpta Sleumer & Uso madeireiro (CNCFlora 2012). \\
\hline Rubiaceae & $\begin{array}{l}\text { Melanopsidium nigrum } \\
\text { Colla }\end{array}$ & $\begin{array}{l}\text { Consumo in natura de seus frutos, além de ter uso direto, de escala local, em cabos de } \\
\text { ferramentas e lenha (CNCFlora 2012). }\end{array}$ \\
\hline Sapindaceae & Cupania furfuraceae Radlk. & Uso da sua madeira para a produção de lenha (CNCFlora 2012). \\
\hline
\end{tabular}


Tabela 4. Espécies com Dados Insuficientes (DD) presentes na Ilha Grande, Angra dos Reis, Rio de Janeiro, Brasil. Legenda: * Espécies classificadas pelo Catálogo da Flora do Estado do Rio de Janeiro (2014); PEIG-VC = Parque Estadual da Ilha Grande - vertente continental; PEIG-VO = Parque Estadual da Ilha Grande - vertente oceânica; RBEPS = Reserva Biológica Estadual da Praia do Sul.

\begin{tabular}{|c|c|c|c|c|c|c|c|}
\hline Família & Espécie & $\begin{array}{l}\text { Endêmica } \\
\text { Brasil }\end{array}$ & $\begin{array}{l}\text { Distribuição } \\
\text { geográfica Brasil }\end{array}$ & Referência & $\begin{array}{l}\text { PEIG } \\
\text { VC }\end{array}$ & $\begin{array}{l}\text { PEIG } \\
\text { VO }\end{array}$ & RBEPS \\
\hline Asteraceae & $\begin{array}{l}\text { Vernonanthura lindbergii } \\
\text { (Baker) H.Rob. }\end{array}$ & $X$ & $\mathrm{MG} / \mathrm{RJ} / \mathrm{SP} / \mathrm{PR}$ & Manão (2011) & & $X$ & \\
\hline Bromeliaceae & $\begin{array}{l}\text { Billbergia pyramidalis (Sims) } \\
\text { Lindl. }\end{array}$ & & $\begin{array}{l}\mathrm{BA} / \mathrm{ES} / \mathrm{MG} / \mathrm{RJ} \\
\mathrm{SP} / \mathrm{PR}\end{array}$ & $\begin{array}{l}\text { Almeida et al. (1998); } \\
\text { Callado et al. (2009); } \\
\text { Nunes-Freitas et al. } \\
\text { (2009); Manão (2011) }\end{array}$ & $\mathrm{X}$ & $X$ & \\
\hline Bromeliaceae & Tillandsia recurvifolia Hook. & $\mathrm{X}$ & $\mathrm{RJ} / \mathrm{SP} / \mathrm{PR} / \mathrm{SC}$ & Manão (2011) & & $\mathrm{X}$ & \\
\hline Cactaceae & Rhipsalis crispata (Haw.) Pfeiff. & $\mathrm{X}$ & $\mathrm{BA} / \mathrm{PE} / \mathrm{RJ} / \mathrm{SP} / \mathrm{SC}$ & $\begin{array}{l}\text { Araújo \& Oliveira } \\
(1988)\end{array}$ & & & $\mathrm{X}$ \\
\hline Commelinaceae & $\begin{array}{l}\text { *Commelina rufipes Seub. } \\
\text { var. rufipes }\end{array}$ & & $\begin{array}{l}\mathrm{AC} / \mathrm{AM} / \mathrm{BA} / \mathrm{ES} \\
\mathrm{MT} / \mathrm{MG} / \mathrm{PA} / \mathrm{PE} \\
\mathrm{RJ} / \mathrm{SP}\end{array}$ & $\begin{array}{l}\text { Aona \& Pellegrini } \\
(2014)\end{array}$ & $X$ & $\mathrm{X}$ & $\mathrm{X}$ \\
\hline Euphorbiaceae & *Acalypha gracilis Spreng. & $X$ & $\begin{array}{l}\mathrm{AL} / \mathrm{BA} / \mathrm{CE} / \mathrm{DF} / \mathrm{GO} \\
\mathrm{MS} / \mathrm{MG} / \mathrm{PA} / \mathrm{PB} / \mathrm{PR} \\
\mathrm{RJ} / \mathrm{RS} / \mathrm{SC} / \mathrm{SP}\end{array}$ & Oliveira (2014) & $\mathrm{X}$ & $X$ & \\
\hline Gentinaceae & Voyria aphylla (Jacq.) Pers. & & $\begin{array}{l}\mathrm{AM} / \mathrm{AP} / \mathrm{PA} / \mathrm{RR} \\
\mathrm{BA} / \mathrm{CE} / \mathrm{PB} / \mathrm{PE} \\
\mathrm{SE} / \mathrm{MT} / \mathrm{ES} / \mathrm{MG} \\
\mathrm{RJ} / \mathrm{SP} / \mathrm{PR} / \mathrm{SC}\end{array}$ & $\begin{array}{l}\text { Araújo \& Oliveira } \\
\text { (1988); Callado et al. } \\
\text { (2009); Manão (2011) }\end{array}$ & $X$ & $\mathrm{X}$ & $X$ \\
\hline Menispermaceae & $\begin{array}{l}\text { Chondrodendron platiphyllum } \\
\text { (A.St.-Hil.) Miers }\end{array}$ & $\mathrm{X}$ & $\begin{array}{l}\mathrm{BA} / \mathrm{CE} / \mathrm{PB} / \mathrm{PE} \\
\mathrm{RN} / \mathrm{ES} / \mathrm{MG} \\
\mathrm{RJ} / \mathrm{SP}\end{array}$ & Callado et al. (2009) & & $\mathrm{X}$ & \\
\hline Menispermaceae & $\begin{array}{l}\text { Disciphania hernandia (Vell.) } \\
\text { Barneby }\end{array}$ & $\mathrm{X}$ & $\mathrm{BA} / \mathrm{RJ}$ & Andrade (2015) & & $X$ & \\
\hline Orchidaceae & $\begin{array}{l}\text { Warczewiczella wailesiana } \\
\text { (Lindl.) Rchb.f. ex E.Morren }\end{array}$ & $X$ & $\begin{array}{l}\mathrm{BA} / \mathrm{ES} / \mathrm{MG} / \mathrm{RJ} \\
\mathrm{RJ} / \mathrm{SP}\end{array}$ & Manão (2011) & & $\mathrm{X}$ & \\
\hline Piperaceae & $\begin{array}{l}\text { Peperomia distachya } \\
\text { (L.) A.Dietr. }\end{array}$ & & $\mathrm{RJ} / \mathrm{SP}$ & $\begin{array}{l}\text { Callado et al. (2009); } \\
\text { Manão (2011) }\end{array}$ & & $\mathrm{X}$ & \\
\hline Solanaceae & $\begin{array}{l}\text { *Aureliana fasciculata var. } \\
\text { tomentella (Sendtn.) Barboza } \\
\text { \& A.T.Hunz. }\end{array}$ & & $\begin{array}{l}\mathrm{ES} / \mathrm{MG} / \mathrm{RJ} / \mathrm{SP} \\
\mathrm{PR} / \mathrm{SC} / \mathrm{RS}\end{array}$ & Bandeira (2014) & $X$ & $\mathrm{X}$ & \\
\hline Solanaceae & $\begin{array}{l}\text { *Dyssochroma viridiflorum } \\
\text { (Sims) Miers }\end{array}$ & $\mathrm{X}$ & $\begin{array}{l}\mathrm{BA} / \mathrm{CE} / \mathrm{PE} / \mathrm{ES} / \mathrm{MG} \\
\mathrm{RJ} / \mathrm{SP} / \mathrm{PR}\end{array}$ & Bandeira (2014) & & & $X$ \\
\hline Solanaceae & *Solanum argenteum Dunal & $\mathrm{X}$ & $\begin{array}{l}\mathrm{DF} / \mathrm{GO} / \mathrm{ES} / \mathrm{MG} / \mathrm{RJ} \\
\mathrm{SP} / \mathrm{PR}\end{array}$ & Bandeira 2014. & $\mathrm{X}$ & $\mathrm{X}$ & $\mathrm{X}$ \\
\hline Solanaceae & *Solanum carautae Carvalho & $\mathrm{X}$ & $\mathrm{ES} / \mathrm{RJ}$ & Bandeira (2014) & & & $\mathrm{X}$ \\
\hline Solanaceae & $\begin{array}{l}\text { *Solanum decompositiflorum } \\
\text { Sendtn. }\end{array}$ & $X$ & $\begin{array}{l}\mathrm{BA} / \mathrm{PE} / \mathrm{DF} / \mathrm{GO} / \mathrm{ES} \\
\mathrm{MG} / \mathrm{RJ} / \mathrm{SP} / \mathrm{PR}\end{array}$ & Bandeira (2014) & & & $\mathrm{X}$ \\
\hline Solanaceae & *Solanum mauritianum Scop. & & $\begin{array}{l}\mathrm{ES} / \mathrm{MG} / \mathrm{RJ} / \mathrm{SP} \\
\mathrm{PR} / \mathrm{SC} / \mathrm{RS}\end{array}$ & Bandeira (2014) & & & $\mathrm{X}$ \\
\hline Solanaceae & $\begin{array}{l}\text { *Solanum pseudoquina } \\
\text { A.St.-Hil. }\end{array}$ & & $\begin{array}{l}\mathrm{BA} / \mathrm{ES} / \mathrm{MG} / \mathrm{RJ} / \mathrm{SP} \\
\mathrm{PR} / \mathrm{SC} / \mathrm{RS}\end{array}$ & Bandeira (2014) & & & $X$ \\
\hline
\end{tabular}

Dentre todas as espécies ameaçadas levantadas, apenas 23 espécies apresentaram dados de coordenadas geográficas suficientes para formar um polígono para o cálculo da $\mathrm{AOO}$ e EOO, permitindo a avaliação do estado de ameaça dessas espécies na Ilha Grande (Tabelas 1 e 5). Apenas Anthurium luschnathianum (Araceae) e Bertolonia valenteana (Melastomataceae) mantiveram as mesmas categorias estabelecidas pelo CNCFlora (2012). Destaque para a espécie Pleroma thereminiana (Melastomataceae), classificada como EN por Baumgratz et al. (2018) na Lista Vermelha das espécies endêmicas do estado do Rio de Janeiro, é aqui classificada como CR. 
Tabela 5. Espécies da flora presentes na Lista Vermelha de espécies ameaçadas da Ilha Grande, Angra dos Reis, Rio de Janeiro, Brasil, avaliadas pela sua Área de Ocupação (AOO) e Extensão de Ocorrência (EOO) na Ilha Grande. Status Ilha Grande (IG): CR = Criticamente em Perigo; EN = Em Perigo.

\begin{tabular}{|c|c|c|c|}
\hline Espécie & $\mathrm{AOO}$ & EOO & Status IG \\
\hline Aechmea gracilis Lindm. & $12 \mathrm{~km}^{2}$ & $2,126 \mathrm{~km}^{2}$ & $\mathrm{CR}$ \\
\hline Anthurium luschnathianum Kunth & $24 \mathrm{~km}^{2}$ & $47,650 \mathrm{~km}^{2}$ & $\mathrm{EN}$ \\
\hline Aristolochia odora Steud. & $8 \mathrm{~km}^{2}$ & $0,093 \mathrm{~km}^{2}$ & CR \\
\hline Aureliana fasciculata (Vell.) Sendtn. & $20 \mathrm{~km}^{2}$ & $22,781 \mathrm{~km}^{2}$ & CR \\
\hline Bertolonia valenteana Baumgratz & $12 \mathrm{~km}^{2}$ & $2,617 \mathrm{~km}^{2}$ & CR \\
\hline Calyptranthes fusiformis M.L.Kawas. & $8 \mathrm{~km}^{2}$ & $1,248 \mathrm{~km}^{2}$ & CR \\
\hline Cattleya guttata Lindl. & $8 \mathrm{~km}^{2}$ & 0 & CR \\
\hline Euterpe edulis Mart. & $8 \mathrm{~km}^{2}$ & $1,093 \mathrm{~km}^{2}$ & CR \\
\hline Hippeastrum striatum (Lam.) Moore & $8 \mathrm{~km}^{2}$ & 0 & $\mathrm{CR}$ \\
\hline Goeppertia aemula (Körn.) Borchs \& Suárez & $12 \mathrm{~km}^{2}$ & $0,202 \mathrm{~km}^{2}$ & $\mathrm{EN}$ \\
\hline Maranta subterranea J.M.A.Braga & $8 \mathrm{~km}^{2}$ & 0 & $\mathrm{CR}$ \\
\hline Melanopsidium nigrum Colla & $8 \mathrm{~km}^{2}$ & $0,084 \mathrm{~km}^{2}$ & CR \\
\hline Meriania longipes Triana & $12 \mathrm{~km}^{2}$ & $2,372 \mathrm{~km}^{2}$ & CR \\
\hline Mikania argyreiae DC. & $12 \mathrm{~km}^{2}$ & $5,450 \mathrm{~km}^{2}$ & CR \\
\hline Piper scutifolium Yunck. & $8 \mathrm{~km}^{2}$ & 0 & CR \\
\hline Pleroma thereminiana (DC.) Triana & $4 \mathrm{~km}^{2}$ & 0 & CR \\
\hline Rhipsalis oblonga Loefgr. & $12 \mathrm{~km}^{2}$ & $0,227 \mathrm{~km}^{2}$ & EN \\
\hline Rudgea macrophylla Benth & $8 \mathrm{~km}^{2}$ & $0,750 \mathrm{~km}^{2}$ & $\mathrm{CR}$ \\
\hline Solanum argenteum Dunal & $16 \mathrm{~km}^{2}$ & $4,578 \mathrm{~km}^{2}$ & CR \\
\hline Voyria aphylla (Jacq.) Pers. & $16 \mathrm{~km}^{2}$ & $4,172 \mathrm{~km}^{2}$ & CR \\
\hline Vriesea rodigasiana E.Morren & $8 \mathrm{~km}^{2}$ & $0,029 \mathrm{~km}^{2}$ & CR \\
\hline Xylopia brasiliensis Spreng. & $12 \mathrm{~km}^{2}$ & $8,941 \mathrm{~km}^{2}$ & $\mathrm{EN}$ \\
\hline Wittrockia superba Lindm. & $8 \mathrm{~km}^{2}$ & $3,773 \mathrm{~km}^{2}$ & CR \\
\hline
\end{tabular}

\section{DISCUSSÃO}

As ilhas constituem ecossistemas autônomos delimitados, com seu próprio agrupamento único de biodiversidade, que é frequentemente limitado (Marin 2004). Elas possuem a mais alta proporção de registros de extinção de espécies e continuam a ser significativamente ameaçadas por espécies exóticas invasoras, mudanças climáticas, desastres naturais e ambientais, degradação de terras e fontes terrestres da poluição marinha (CBD 2006). Dessa forma, encontram-se sob sérias ameaças e constituem prioridades globais para a conservação. Apesar de a Ilha Grande ser afastada do continente por apenas 2,0 km de distância, aparece como área prioritária para conservação com importância extremamente alta (MMA 2007).

O conhecimento da Flora da Ilha Grande ainda apresenta grandes lacunas (Callado et al. 2009), pois os estudos mais generalistas sobre a flora realizados na Ilha Grande, como de Araújo \& Oliveira (1988), Sampaio (1997), Callado et al. (2009), Manão (2011), INEA(2013) e Andrade (2015), apontam áreas de amostragem consideradas pequenas em relação a área total da ilha e em áreas de maiores alterações de modificação da paisagem.
Manão (2011) afirmou que o conhecimento relativo à riqueza florística na Ilha Grande encontra-se até o momento insuficiente em muitos trechos de floresta, devido à dificuldade de acesso a determinadas áreas, ao baixo esforço de coleta para determinados grupos botânicos e aos fatores climáticos adversos. Nunes-Freitas et al. (2009) em sua revisão da lista de Bromeliaceae ocorrentes na Ilha Grande, informaram que um dos principais fatores para o aumento do número de espécies registradas na Ilha Grande foi a realização de amostragens em todas as formações vegetais e em quase todas as áreas da Ilha Grande.

A possibilidade do pesquisador escolher áreas de estudo com maior acessibilidade pode ocasionar a exclusão do conhecimento de espécies raras ou que possuam algum risco de extinção. $\mathrm{O}$ endemismo é uma das características mais marcantes do bioma Mata Atlântica (Marques et al. 2016), e determinadas espécies são restritas a regiões muito específicas, aumentando a probabilidade de uma espécie desaparecer antes mesmo de ser descoberta. Um exemplo de espécie endêmica da região da costa verde do Rio de Janeiro, e que tem ocorrência na Ilha Grande, é Pleroma thereminiana (Melastomataceae) (Callado et al. 2009; Manão 2011; Pinheiro 2013). De acordo com 
Pinheiro (2013), P. thereminiana ocorre em áreas abertas, em paredões de solo argiloso e próximo a constantes fluxos de água, e foi registrada em área degradada na Ilha Grande, ocorrendo em local em processo erosivo e com solo exposto, dominado pela invasora Pteridium arachnoideum (Kaulf.) Maxon, e em topo de morro na porção central da ilha.

Observa-se que o maior número das espécies aparece nas vertentes sul, sudeste e leste da Ilha Grande, coincidentemente são áreas com trilhas de maior acesso, e o principal trajeto entre o Centro de Estudos Ambientais e Desenvolvimento Sustentável (CEADS), a Vila do Abraão e a RBEPS. Oliveira (2002) ressaltou que a vertente sul e o centro geográfico da Ilha Grande apresentam vegetação em melhor estado de conservação. Ressalta-se ainda que existem muitas lacunas de distribuição geográfica das espécies na Ilha Grande, visto que não há nenhum inventário florístico e/ou florestal na porção oeste e norte da Ilha Grande, impossibilitando o conhecimento do número total de espécies que ocorram na Ilha Grande, assim como o número total de espécies em estado de ameaça.

$\mathrm{O}$ fato dessas amostras aparecerem somente nestas regiões não significa que as espécies ameaçadas apenas ocorram nestas áreas, e sim, que há falta de inventários e amostragens para a região central, além das vertentes norte e oeste da ilha. Uma das justificativas da escassez de amostragem para essas áreas voltadas para o continente é provavelmente a grande concentração de área urbana. De acordo com Oliveira (2002), a vertente norte, assim como as áreas próximas aos povoados e vilas, está coberta por vegetação degradada e áreas recentes de capoeira, com 5 a 25 anos de regeneração.

Na Ilha Grande, as trilhas são a principal forma de conexão entre os diferentes núcleos populacionais, sendo acessadas por milhares de pessoas anualmente sem nenhum controle do Órgão Ambiental Estadual. Por mais conflitante que seja tratar de degradação ambiental em áreas protegidas, com a instauração do ciclo econômico baseado atualmente no turismo, cabe a análise de como as espécies com risco de extinção se adaptam a esse modelo, pois a sua principal ameaça é a pressão antrópica relacionada ao desmatamento causado pela especulação imobiliária e atividades agrícolas, reduzindo os remanescentes florestais a pequenos fragmentos.

O percurso correspondente ao trecho Abraão-Lopes Mendes foi considerado por Rodrigues et al. (2016), com o maior número de impactos negativos e erosão, apresentando trilhas mal conservadas, sem sinalização e sem adequado monitoramento pelo órgão ambiental responsável por seu manejo. Além da inexistência de uma política de conscientização ambiental, informando aos turistas e moradores o que é permitido ou não em Unidades de Conservação, essas trilhas são consideradas vetores de pressão antrópica e causam degradação ao meio ambiente. $\mathrm{O}$ fato destas espécies estarem em trilhas de múltiplos usos (população e turismo) pode levar aos seus desaparecimentos na Ilha Grande, pois na medida em que se intensifica a visitação pública em ambientes de elevada fragilidade, sem planejamento adequado, coloca-se em risco a dinâmica ambiental ou a integridade ecológica dos espaços preservados (Rodrigues et al. 2016).

Apesar da literatura analisada não informar o valor ornamental da maioria das espécies herbáceas encontradas em estado de ameaça no presente estudo, deve-se ter atenção redobrada em relação às espécies das famílias Araceae, Bromeliaceae e Orchidaceae, em especial a espécie endêmica do estado do Rio de Janeiro Acianthera subrotundifolia (Orchidaceae), e as espécies Cattleya guttata Lindl., Epidendrum hololeucum Barb.Rodr., Grandiphyllum hians (Lindl.) Docha Neto, Rauhiella silvana Toscano (Orchidaceae), e Rhipsalis oblonga Loefgr. (Cactaceae), legalmente protegidas de acordo com a convenção sobre o comércio internacional de espécies selvagens da flora e fauna (UNEP-WCMC 2019), pois apresentam alto valor comercial para contrabandistas e colecionadores.

A remoção dos representantes dessas famílias sem que tenham completado seu ciclo reprodutivo, ou quando retiradas por completo (raiz, caule, folha e flores), como é o caso de algumas bromélias e orquídeas, podem acarretar na extinção dessas espécies. Observa-se também que espécies ameaçadas são utilizadas como refúgio e alimentos para a fauna e seu desaparecimento poderia ocasionar uma série de impactos em cadeia. Segundo Barroso et al. (2007), a extração de plantas para a comercialização configura uma das principais causas da extinção, pois parte considerável das espécies raras ou ameaçadas tem notável potencial ornamental ou econômico.

A etapa subsequente da avaliação de risco de extinção das espécies, é a criação de subsídios para a retirada das espécies da lista vermelha. Assim sendo, o planejamento de ações para a conservação (PAN) atua no sentido de reunir todas as informações relativas a áreas prioritárias, dados sobre as espécies e políticas públicas, e elaborar uma série de ações para mitigar as ameaças que incidem nos diversos territórios. As medidas indicadas pelo PAN são importantes para as tomadas de decisões políticas e estão citadas na Portaria MMA No 443, de 17 de dezembro de 2014, a qual reconhece a flora brasileira ameaçada de extinção.

\section{AGRADECIMENTOS}

As autoras agradecem ao professor Dr. Luís Felipe Skinner pela produção do mapa da Figura 1 no software QGIS.

\section{REFERÊNCIAS}

Almeida, D.R., Carvalho, L.C. \& Rocha, C.F.D. 1998. As bromélias da mata atlântica da Ilha Grande, RJ: composição e diversidade de espécies em três ambientes diferentes. Revista Bromélia 5(1):54-65.

Andrade, L.R. 2015. Comunidades de trepadeiras, em gradientes sucessionais de floresta atlântica em Ilha Grande, Angra dos Reis, RJ. Tese de Doutorado, 143f., Escola Nacional de Botânica Tropical, Instituto de Pesquisas Jardim Botânico do Rio de Janeiro, Rio de Janeiro.

Antonini, R.D. \& Nunes-Freitas, A.F. 2004. Estrutura populacional e distribuição espacial de Miconia prasina D.C. (Melastomataceae) 
em duas áreas de Floresta Atlântica na Ilha Grande, RJ, Sudeste do Brasil. Acta Botanica Brasilica 18(3):671-676.

Aona, L. \& Pellegrini, M.O.O. 2014. Commelinaceae. In: Catálogo das espécies de plantas vasculares e briófitas do Estado do Rio de Janeiro. Instituto de Pesquisas Jardim Botânico do Rio de Janeiro, Rio de Janeiro. Disponível em: http://florariojaneiro.jbrj.gov.br. Acessado em 12.11. 2017.

Araújo, C.D., Carvalho, A.G. \& Silva, C.D. 2005. Impactos ambientais do turismo na Ilha Grande: um estudo comparativo sobre a percepção dos moradores da Vila do Abraão e da Vila Dois Rios. Caderno Virtual de Turismo 5(3):18-26.

Araujo, D.S.D. \& Oliveira, R.R. 1988. Reserva Biológica Estadual da Praia do Sul (Ilha Grande, estado do Rio de Janeiro): Lista Preliminar da Flora. Acta Botanica Brasilica 1(2):83-94.

Bandeira, B.C. 2014. Solanaceae. In: Catálogo das espécies de plantas vasculares e briófitas do Estado do Rio de Janeiro. Instituto de Pesquisas Jardim Botânico do Rio de Janeiro, Rio de Janeiro. Disponível em: http://florariojaneiro.jbrj.gov.br. Acessado em 12.11.2017.

Barroso, C.M., Klein, G.N., Barros, I.B.I., Franke, L.B. \& Delwing A.B. 2007. Considerações sobre a propagação e o uso ornamental de plantas raras ou ameaçadas de extinção no Rio Grande do Sul, Brasil. Revista Brasileira de Horticultura Ornamental 13(2):91.

Baumgratz, J.F.A., Coelho, M.A.N., Peixoto, A.L., Mynssen, C.M., Bediaga, B.E.H., Costa, D.P., Dalcin, E., Guimarães, E.F., Martinell, G., Silva, D.S.P., Sylvestre, L.S., Freitas, M.F., Morim, M.P. \& Forzza, R.C. 2014. Catálogo das Espécies de Plantas Vasculares e Briófitas do Estado do Rio de Janeiro. Instituto de Pesquisas Jardim Botânico do Rio de Janeiro. Disponível em: http://florariojaneiro. jbrj.gov.br/. Acessado em 12.11.2017.

Baumgratz, J.F., Gonçalves, K.C.S., Rosa, P., Santos Filho, L., Negrão, R., Amaro, R., Messina, T., Moraes, M., Wimmer, F., Margon, H., Avancini, R., Novaes, L., Amorim, T., Braga, R. \& Menezes, V. 2018. Melastomataceae. In: Livro Vermelho da Flora Endêmica do Estado do Rio de Janeiro (G. Martinelli, E. Martins, M. Moraes, R. Loyola \& R. Amaro, orgs.), Jardim Botânico do Rio de Janeiro / SEA - Secretaria de Estado do Ambiente / Andrea Jakobsson Estúdio, Rio de Janeiro, p. 317-340.

BFG - The Brazil Flora Group. 2015. Growing knowledge: an overview of Seed Plant diversity in Brazil. Rodriguésia 66(4):1085-1113.

Bourscheid, K., Siminski, A., Fantini, A.C. \& Mac Fadden, J. 2011. Euterpe edulis - Palmito-juçara. In: Espécies nativas da flora brasileira de valor econômico atual ou potencial: plantas para o futuro - Região Sul (L. Coradin, A. Siminski \& A. Reis, eds.), MMA - Ministério do Meio Ambiente, Brasília, p. 178-183.

Callado, C.H., Barros, A.A.M., Ribas, L.A., Albarello, N., Gagliardi, R. $\&$ Jascone, C.E. 2009. Flora e cobertura vegetal. In: O ambiente da Ilha Grande (M. Bastos \& C.H. Callado, orgs.), Centro de Estudos Ambientais e Desenvolvimento Sustentável, Universidade do Estado do Rio de Janeiro, Rio de Janeiro, p. 91-161.

Calazans, L. 2014. Philodendron (Araceae). In: Catálogo das espécies de plantas vasculares e briófitas do Estado do Rio de Janeiro. Instituto de Pesquisas Jardim Botânico do Rio de Janeiro, Rio de Janeiro. Disponível em: http://florariojaneiro.jbrj.gov.br. Acessado em 12.11. 2017.

Capellari Jr., L. 2002. Aristolochiaceae. In: Flora Fanerogâmica do Estado de São Paulo, vol. 2 (M.G.L. Wanderley, G.J. Shepherd, A.M. Giulietti, T.S. Melhem, V. Bittrich \& C. Kameyama, eds.), Instituto de Botânica, São Paulo, p: 39-50.

CBD - Convention on Biological Diversity. 2006. Report of eighth meeting of the parties to the Convention on Biological Diversity. Decision VIII/1. UNEP/CBD/COP/8/31. Disponível em: https://www.cbd. int/meetings/COP-08 e versão em português http://www.mma.gov. br/estruturas/sbf_chm_rbbio/_arquivos/decisao\%20cop\%201.pdf. Acessado em 20.11. 2017.

CNCFlora - Centro Nacional de Conservação da Flora. 2012. Disponível em http://cncflora.jbrj.gov.br/. Acessado em 15.11. 2017.

Coelho, M.A.N., Baumgratz, J.F.A., Lobão, A.Q., Sylvestre, L.S., Trovó, M. \& Silva, A.E. 2017. Flora do estado do Rio de Janeiro: avanços no conhecimento da diversidade. Rodriguésia 68(1):1-11. DOI: 10.1590/2175-7860201768101
Costa, A.F., Santos-Silva, F., Martinelli, G., Versieux, L.M., Louzada, R., Amaro, R., Santos Filho, L., Messina, T., Wimmer, F., Maurenza, D., Amorim, T., Novaes, L. \& Menezes, V. 2018. Bromeliaceae. In: Livro Vermelho da Flora Endêmica do Estado do Rio de Janeiro (G. Martinelli, E. Martins, M. Moraes, R. Loyola \& R. Amaro, orgs.), Jardim Botânico do Rio de Janeiro / SEA - Secretaria de Estado do Ambiente / Andrea Jakobsson Estúdio, Rio de Janeiro, p. 176-206.

Costa, L.C.B., Rocha, E.A., Silva, L.A.M., Jardim, J.G., Silva, D.C., Gaião, L.O. \& Moreira, R.C.T. 2006. Levantamento preliminar das espécies vegetais com potencial econômico no Parque Municipal da Boa Esperança, Ilhéus, Bahia, Brasil. Acta Farmaceutica Bonaerense 25(2):184-191.

Cruz, A.C.R. \& Nunes-Freitas, A.F. 2017. Diversidade e Conservação das Epífitas Vasculares da Ilha Grande, RJ. In: Anais $6^{\circ}$ Simpósio de Gestão Ambiental e Biodiversidade (M.A. Milward-de-Azevedo \& E. Cortines, orgs.), Departamento de Ciências do Meio Ambiente, Instituto Três Rios, Universidade Federal Rural do Rio de Janeiro, Três Rios, p.18-24.

Dean, W. 2004. A ferro e fogo: a história e a devastação da Mata Atlântica. Companhia das Letras, São Paulo. 484p.

Diegues, A.C. 2000. Etnoconservação: novos rumos para a proteção da natureza nos trópicos. Hucitec, São Paulo. 290p.

Esbérard, C.E.L., Nogueira, T.J., Luz, J.L., Melo, G.G.S., Mangolin, R., Jucá, N., Raíces, D.S.L., Enrici, M.C. \& Bergallo, H. 2006. Morcegos da Ilha Grande, Angra dos Reis, RJ, Sudeste do Brasil. Revista Brasileira de Zoociencias 8(2):147-153.

Flora do Brasil 2020. Jardim Botânico do Rio de Janeiro. Disponível em: http://floradobrasil.jbrj.gov.br/. Acessado em 28.09.2018.

Gama, S.V.G., Leal Filha, S.M. \& Rocha, I.C. 2006. Os impactos ambientais e o processo de gestão integrada: experiências na Vila de Abraão - Ilha Grande, Angra dos Reis (RJ). Revista Sociedade \& Natureza 18(35):131-149.

Gama, S.V.G., Silva, L.G.A.E. \& Salgado, C.M. 2009. Geologia, relevo e solos. In: O ambiente da Ilha Grande (M. Bastos \& C.H. Callado, orgs.), Centro de Estudos Ambientais e Desenvolvimento Sustentável, Universidade do Estado do Rio de Janeiro, Rio de Janeiro, p. 21-64.

GEOCAT - Geospatial Conservation Assessment Toll. Disponível em: http:/geocat.kew.org/editor. Acessado em 07.04.2016.

Giordano, L.C. 2014. Humiriaceae. In: Catálogo das espécies de plantas vasculares e briófitas do Estado do Rio de Janeiro. Instituto de Pesquisas Jardim Botânico do Rio de Janeiro, Rio de Janeiro. Disponível em: http://florariojaneiro.jbrj.gov.br. Acessado em 12.11. 2017.

Grings, M. \& Brack, P. 2011. Cedrela fissilis - Cedro. In: Espécies nativas da flora brasileira de valor econômico atual ou potencial: plantas para o futuro - Região Sul (L. Coradin, A. Siminski \& A. Reis, eds.), MMA - Ministério do Meio Ambiente, Brasília, p. 444-447.

Instituto Brasileiro de Geografia e Estatística - IBGE. 2012. Manuais técnicos em geociências $n^{\circ} 1$ : manual técnico da vegetação brasileira: Sistema fitogeográfico Inventário das formações florestais e campestres Técnicas e manejo de coleções botânicas Procedimentos para mapeamentos. $2^{\text {a }}$. ed., IBGE, Rio de Janeiro. 275p.

Instituto Estadual do Ambiente - INEA. 2013. Parque Estadual da Ilha Grande: plano de manejo (fase 2) - resumo executivo. Instituto Estadual do Ambiente. INEA, Rio de Janeiro. 100p.

International Union for Conservation of Nature - IUCN. 2017. The IUCN Red List of Threatened Species. Disponível em: http://www. iucnredlist.org/. Acessado em 12.05. 2017.

Lorenzi, H. 2002a. Árvores brasileiras: manual de identificação e cultivo de plantas arbóreas nativas do Brasil. Vol.1, 4ª . ed., Instituto Plantaurum, Nova Odessa. 368p

Lorenzi, H. 2002b. Árvores brasileiras: manual de identificação e cultivo de plantas arbóreas nativas do Brasil. Vol. 2, 2a . ed., Instituto Plantaurum, Nova Odessa. 368p.

Lorenzi, H. 2009. Árvores brasileiras: manual de identificação e cultivo de plantas arbóreas nativas do Brasil. Vol. 3, 1 ${ }^{\text {a }}$. ed., Instituto Plantaurum, Nova Odessa. 384p.

Lorenzi, H. 2010. Flora Brasileira - Arecaceae (Palmeiras). $1^{\text {a }}$. ed., Instituto Plantaurum, Nova Odessa. 384p. 
Lorenzi, H. \& Souza, H.M. 2008. Plantas Ornamentais no Brasil: arbustivas, herbáceas e trepadeiras. $4^{\text {a }}$. ed., Instituto Plantaurum, Nova Odessa. 368p. 1088p.

Loyola, R., Machado, N., Nova, D.V., Martins, E. \& Martinelli, G. 2014. Áreas prioritárias para a conservação e uso sustentável da flora brasileira ameaçada de extinção. Instituto de Pesquisas Jardim Botânico do Rio de Janeiro, Rio de Janeiro. 80p.

Machado, N., Negrão, R., Martins, E., Loyola, R., Amaro, R., Moraes, M., Rosa, P., Baez, C., Moraes, L., Costa, M.L., Wimmer, F., Margon, H., Dalcin, E. \& Martinelli, G. 2018. Espécies ameaçadas da flora endêmica do estado do Rio de Janeiro. In: Livro Vermelho da Flora Endêmica do Estado do Rio de Janeiro (G. Martinelli, E. Martins, M. Moraes, R. Loyola \& R. Amaro, orgs.), Jardim Botânico do Rio de Janeiro / SEA - Secretaria de Estado do Ambiente / Andrea Jakobsson Estúdio, Rio de Janeiro, p. 97-117.

Magalhães, M.A.F. 2008. Procedimentos para revisão de plano de manejo: Parque Estadual da Ilha Grande, RJ. Monografia de Bacharelado, 81 f., Universidade Federal Rural do Rio de Janeiro, Seropédica.

Manão, C.Y.G. 2011. Composição florística e estrutura da comunidade arbustivo-arbórea de um trecho de floresta submontana na vertente sudeste do Parque Estadual da Ilha Grande, Angra dos Reis, RJ. Dissertação de Mestrado, 148 f., Universidade do Estado do Rio de Janeiro, Rio de Janeiro.

Marin, C. 2004. Introduction. In: Deda, P., Marin, C. \& Mulongoy, K.J. Island biodiversity - Sustaining life in vulnerable ecosystems. Special Issue. International Journal on Island Affairs - INSULA, Paris, p. 7-8.

Marques, M.C.M., Silva, A.C.L., Rajão, H., Rosado, B.H.P., Barros, C.F., Oliveira, J.A., Finotti, R., Neckel-Oliveira, S., Amorim, A., Cerqueira, R. \& Bergallo, H.G. 2016. Mata Atlântica - O desafio de transformar um passado de devastação em um futuro de conhecimento e conservação. In: Conhecendo a Biodiversidade (A.L. Peixoto, J.R.P. Luz \& M.A. Brito, orgs.), Editora Vozes, Brasília, p. 50-67.

Martinelli, G. \& Moraes, M.A. 2013. Livro vermelho da Flora do Brasil. 1. ed., Instituto de Pesquisas Jardim Botânico do Rio de Janeiro, Rio de Janeiro. 1102p.

Martinelli, G., Martins, E., Moraes, M., Loyola, R. \& Amaro, R. 2018. Livro Vermelho da Flora Endêmica do Estado do Rio de Janeiro. Jardim Botânico do Rio de Janeiro / SEA - Secretaria de Estado do Ambiente / Andrea Jakobsson Estúdio, Rio de Janeiro. 456p.

Maurenza, D., Bocayuva, M., Pougy, N., Martins, E. \& Martinelli, G. 2018. Lista da flora das unidades de conservação estaduais do Rio de Janeiro. $1^{\text {a }}$. ed., Andrea Jakobsson Estúdio, Rio de Janeiro. 420p.

Mendonça, T.C.M. 2008. O turismo que se tem e o turismo que se quer: discursos e significados a propósito do turismo na Vila do Abraão Ilha Grande (Angra dos Reis, RJ). In: Anais V Seminário de Pesquisa em Turismo do MERCOSUL. Disponível em: http://www.ucs.br/ ucs/tplVSeminTur\%20/eventos/seminarios_semintur/semin_tur_5/ trabalhos/arquivos/gt10-07.pdf. Acessado em 01.02. 2017.

Menini Neto, L., Moulton, L., Moraes, M., Meneguzzo, T., Messina, T., Santos Filho, L., Negrão, R., Wimmer, F., Avancini, R., Novaes, L., Margon, H. \& Braga, R. 2018. Orchidaceae. In: Livro Vermelho da Flora Endêmica do Estado do Rio de Janeiro (G. Martinelli, E. Martins, M. Moraes, R. Loyola \& R. Amaro, orgs.), Jardim Botânico do Rio de Janeiro / SEA - Secretaria de Estado do Ambiente / Andrea Jakobsson Estúdio, Rio de Janeiro, p. 365-376.

Ministério do Meio Ambiente - MMA. 2007. Áreas Prioritárias para Conservação, Uso Sustentável e Repartição de Benefícios da Biodiversidade Brasileira: Atualização - Portaria MMA n ${ }^{\circ}$, de 23 de janeiro de 2007. Série Biodiversidade 31. Ministério do Meio Ambiente (MMA), Brasília. 301p. Disponível em: http://www.mma. gov.br/estruturas/chm/_arquivos/biodiversidade31.pdf. Acessado em 05.06. 2018

Ministério do Meio Ambiente - MMA. 2008. Anexo I da Instrução Normativa $\mathrm{n}^{\circ} 6$, de 23 de setembro de 2008. Disponível em: http:// www.mma.gov.br/estruturas/179/_arquivos/179_05122008033615. pdf. Acessado em 05.06. 2018.

Ministério do Meio Ambiente - MMA. 2014. Portaria n443, de 17 de dezembro de 2014. Diário Oficial da União, seção 1, nº 245, 18 de dezembro de 2014. Pp. 110-121. Disponível em: http://cncflora. jbrj.gov.br/portal/static/pdf/portaria_mma_443_2014.pdf. Acessado em 05.06. 2018.

Moura, R. \& Vieira, C.M. 2014. Bromeliaceae. In: Catálogo das espécies de plantas vasculares e briófitas do Estado do Rio de Janeiro. Instituto de Pesquisas Jardim Botânico do Rio de Janeiro, Rio de Janeiro. Disponível em: http://florariojaneiro.jbrj.gov.br. Acessado em 25.10. 2017.

Nadruz, M., Sakuragui, C.M. \& Calazans, L. 2014. Araceae. In: Catálogo das espécies de plantas vasculares e briófitas do Estado do Rio de Janeiro. Instituto de Pesquisas Jardim Botânico do Rio de Janeiro, Rio de Janeiro. Disponível em: http://florariojaneiro.jbrj.gov.br. Acessado em 25.10. 2017.

Nadruz, M., Moraes, L., Wimmer, F., Menezes, V., Amorim, T. \& Novaes, L. 2018. Araceae. In: Livro Vermelho da Flora Endêmica do Estado do Rio de Janeiro (G. Martinelli, E. Martins, M. Moraes, R. Loyola \& R. Amaro, orgs.), Jardim Botânico do Rio de Janeiro / SEA Secretaria de Estado do Ambiente / Andrea Jakobsson Estúdio, Rio de Janeiro, p. 137-143.

Nunes-Freitas, A.F. 2004. Bromeliáceas da Ilha Grande: Variação interhabitats na composição, riqueza e diversidade da comunidade. Tese de Doutorado, 230 f., Universidade do Estado do Rio de Janeiro, Rio de Janeiro.

Nunes-Freitas, A.F., Rocha-Pessoa, T.C., Dias, A.S., Ariani, C.V. \& Rocha, C.F.D. 2009. Bromeliaceae da Ilha Grande: revisão da lista de espécies. Biota Neotropica 9(2): 213-220.

Oliveira, R.R. \& Coelho Netto, A.L. 2001. Captura de nutrientes atmosféricos pela vegetação na Ilha Grande, RJ. Pesquisa Botânica 51:31-49.

Oliveira, A.S. 2014. Euphorbiaceae. In: Catálogo das espécies de plantas vasculares e briófitas do Estado do Rio de Janeiro. Instituto de Pesquisas Jardim Botânico do Rio de Janeiro, Rio de Janeiro. Disponível em: http://florariojaneiro.jbrj.gov.br. Acessado em 12.11. 2017.

Oliveira, R.R. 2002. Ação antrópica e resultantes sobre a estrutura e composição da Mata Atlântica na Ilha Grande, RJ. Rodriguésia 53(82):33-58.

Pinheiro, F.M. 2013. Espécies raras e endêmicas de Melastomataceae no Estado do Rio de Janeiro: padrões de distribuição geográfica e estratégias de conservação. Dissertação de Mestrado, 131 f., Instituto de Pesquisas Jardim Botânico do Rio de Janeiro, Rio de Janeiro.

Rodrigues, L.O., Gama, S.V.G. \& Chirol, A.D. 2016. Diagnóstico das trilhas "Abraão-Pouso", "Pouso-Lopes Mendes" e APA dos Tamoios em Ilha Grande, Angra dos Reis, RJ. Caderno Virtual de Turismo 16(3):123-140.

Salgado, C.M. \& Vasquez, N.D. 2009. Clima. In: O ambiente da Ilha Grande (M. Bastos \& C.H. Callado, orgs.), Centro de Estudos Ambientais e Desenvolvimento Sustentável, Universidade do Estado do Rio de Janeiro, Rio de Janeiro, p. 7-20.

Sampaio, P.D. 1997. Florística e estrutura de floresta atlântica secundária - Reserva Biológica Estadual da Praia do Sul, Ilha Grande, RJ. São Paulo, Dissertação de Mestrado, 113 f., Instituto de Biociências, Universidade de São Paulo, São Paulo.

Scarano, F.R. 2012. Biomas brasileiros: retratos de um país plural. Casa da Palavra, Rio de Janeiro. 304p.

Serafini, T.Z., França, G.B. \& Andriguetto-Filho, J.M. 2010. Ilhas oceânicas brasileiras: biodiversidade conhecida e sua relação com o histórico de uso e ocupação humana. Revista da Gestão Costeira Integrada 10(3):281-301.

Thiers, B.M. 2020. Index Herbariorum: a global directory of public herbaria and associated staff. New York Botanical Garden's Virtual Herbarium. Disponível em: http://sweetgum.nybg.org/ih/. Acessado em 25.09. 2018.

UN Environment World Conservation Monitoring Centre - UNEP-WCMC. 2019. The Checklist of CITES Species Website. CITES Secretariat, Geneva, Switzerland. Compiled by UNEP-WCMC, Cambridge, UK. Disponível em: http://checklist.cites.org. Acessado em 21.09. 2019.

Valejjo, L.R. 2005. Políticas Públicas e Conservação Ambiental: Territorialidades em conflito nos Parques Estaduais da Ilha Grande, da Serra da Tiririca e do Desengano (RJ). Tese de Doutorado, 103 f., Universidade Federal Fluminense, Niterói. 


\section{APÊNDICE}

Materiais examinados: Acianthera subrotundifolia (Cogn.) F.Barros \& V.T.Rodrigues (Orchidaceae): Brasil, Rio de Janeiro, Angra dos Reis, Ilha Grande, 09.XI.2010, M.R.A. Braga 352 (RB). Adenocalymma ubatubense Assis $\&$ Semir (Bignoniaceae): Parque Estadual da Ilha Grande, Vila de Dois Rios, Cachoeira da Mãe D'água, 12.III.2014, D.N.S. Machado 372 (RB). Aechmea gracilis Lindm. (Bromeliaceae): Parque Estadual da Ilha Grande, Estrada para a Vila de Dois Rios, 18.II.2000, C.F.D. Rocha 17 (RBR); Estrada Vila de Dois Rios - Abraão, Trilha do bambuzal, III.2002, A.F. Nunes-Freitas 40 (RBR); Trilha da Praia da Feiticeira, 20.IX.2003, A.F. Nunes-Freitas 86 (RBR); Trilha da Praia da Feiticeira, 19.IX.2003, A.F. Nunes-Freitas 87 (RBR); Trilha da Praia da Feiticeira, 19.IX.2003, A.F. Nunes-Freitas 89 (RBR). Anthurium luschnathianum Kunth (Araceae): Praia do Sul, 06.II.1996, M. Nadruz 1165 (RB); Praia do Sul, 06.II.1996, M. Nadruz 1171 (RB). Aristolochia odora Steud. (Aristochiaceae): Vila do Abraão, 2300'24" S, 44¹9'05”'O, 21.III.1995, O. Yano, M.I.M.N. Oliveira et Silva 23541 (SP); trilha para o Pico do Papagaio, 07.II.2015, E. J. Lírio et al. 1199 (RB). Aureliana fasciculata (Vell.) Sendtn. (Solanaceae): antiga trilha da Praia do Demo em direção ao Canto do Sul, 06.III.2004, J. de C. Silva 05 (RB); Parque Estadual da Ilha Grande, Vila dois Rios, Barra Grande, 04.III.2001, P.W. Feteira 151 (RFFP); Parque Estadual da Ilha Grande, Vila Dois Rios, Cachoeira da Mãe d'Água, 06.III.2002, A.A.M. de Barros 1463 (RFFP); Parque Estadual da Ilha Grande, Estrada Abraão - Dois Rios, descida em direção à Vila Dois Rios, $23^{\circ} 10^{\prime} 29,8^{\prime \prime} \mathrm{S}-44^{\circ} 10^{\prime} 39,9^{\prime \prime} \mathrm{W}, 336$ msm., 29.VIII.2008, A.A.M. de Barros 3284 (RFFP); Parque Estadual da Ilha Grande, Vila Dois Rios, Trilha para Cachoeira da Mãe d'Água, 09.XII.2008, C.R.S. Lamego 12 (RFFP); Parque Estadual da Ilha Grande, Vila

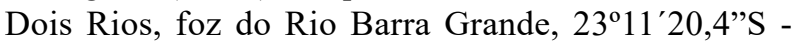
4411'30, '”W, 19.II.2010, A.A.M. de Barros 3812 (RFFP); Vila de Dois Rios, Trilha do Vale (parcela de borda) antes do samambaial, 24.II.2010, C.Y'G. Manão 927 (HRJ); Parque Estadual da Ilha Grande, T12 Pouso - Farol dos Castelhanos, trecho entre a Praia de Lopes Mendes e Praia

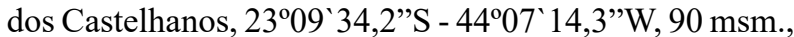
21.III.2010, A.A.M. de Barros 3961 (RFFP). Begonia curtii L.B.Sm. \& B.G.Schub (Begoniaceae): Reserva Biológica da Praia do Sul, Praia do Leste, 28.IX.1989, M.V.S. Alves et D.S.D. Araújo 360 (RB). Begonia undulata Schott (Begoniaceae): Parque Estadual da Ilha Grande, Vila Dois Rios, Mata da Jararaca, 18.I.2002, A.A.M. de Barros 1345 (RFFP). Bertolonia valenteana Baumgratz (Melastomataceae): Serra do Papagaio, 29.VI.1978, J.P.P. Carauta 2971 (MBM, US); Parque Estadual da Ilha Grande, Pico do Papagaio, 25.V.2001, H.C. de Lima 5776 (FLOR, RB); Parque Estadual da Ilha Grande, Estrada Vila do Abraão - Vila Dois Rios (T-14), descida em direção à Vila

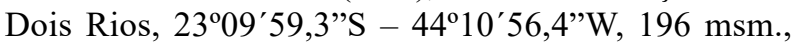
08.XI.2008, A.A.M. de Barros 3462 (RFFP); Parque
Estadual da Ilha Grande, Trilha T-13 para o Pico do

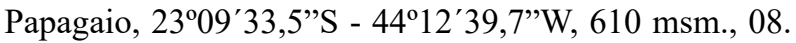
XII.2008, A.A.M. de Barros 3653 (RFFP). Billbergia pyramidalis (Sims) Lindl. (Bromeliaceae): Parque Estadual da Ilha Grande, Mata da trilha para a Praia da Feiticeira, 18.IX.2003, A.F. Nunes-Freitas 90 (RBR); Trilha PalmasMangues, IX.2003, T.C. Rocha-Pessôa 85 (RBR). Goeppertia aemula (Körn.) Borchs \& Suárez (Marantaceae): Parque Estadual da Ilha Grande, Trilha T-16 sentido Vila Dois Rios - Praia de Parnaióca, 05.III.2002, A.A.M. de Barros 1441 (RFFP); Parque Estadual da Ilha Grande, Trilha T-16 sentido Vila Dois Rios - Praia da Parnaioca, $23^{\circ} 10^{\prime} 91,1^{\prime \prime} \mathrm{S}-44^{\circ} 11^{\prime} 04,0^{\prime \prime} \mathrm{W}, 09 . X I .2008$, A.A.M. de Barros 3487 (RFFP). Calyptranthes fusiformis M.L.Kawas. (Myrtaceae): Parque Estadual da Ilha Grande, Vila Dois Rios, Mata da Jararaca, $23^{\circ} 11^{\prime} 00,5^{\prime \prime} \mathrm{S}-44^{\circ} 12^{\prime} 04,2^{\prime \prime} \mathrm{W}$, 110 msm., 15.XI.2015, A.A.M. de Barros 5122 (RFFP); Parque Estadual da Ilha Grande, Vila Dois Rios, Morro

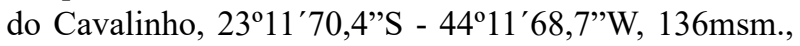
18.VIII.2012, A.A.M. de Barros 4797 (RFFP); Parque Estadual da Ilha Grande, Mata do Caxadaço, próximo da Trilha T-15 sentido Vila Dois Rios - Praia do Caxadaço, 17.I.2002, A.A.M. de Barros 1327 (RFFP). Cattleya guttata Lindl. (Orchidaceae): Parque Estadual da Ilha Grande, Praia de Lopes Mendes, 2309' $98,2^{\prime \prime} \mathrm{S}-44^{\circ} 07^{\prime} 97,6^{\prime \prime} \mathrm{W}$, 19.VIII.2012, A.A.M. de Barros 4807 (RFFP). Cedrela odorata L. (Meliaceae): Parque Estadual da Ilha Grande, Vila Dois Rios, Mata da Jararaca, $23^{\circ} 10^{\prime} 52,92^{\prime \prime}$ S -

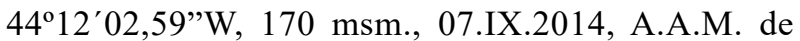
Barros 5064 (RFFP). Chondrodendron platiphyllum (A.St.Hil.) Miers (Menispermaceae): Parque Estadual da Ilha Grande, Vila Dois Rios, Mata da Jararaca, 20.I.2002, A.A.M. de Barros 1376 (RFFP); Parque Estadual da Ilha Grande, Trilha T-16 sentido Vila Dois Rios - Praia da

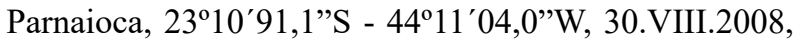
A.A.M. de Barros 3319 (RFFP); Parque Estadual da Ilha Grande, Vila Dois Rios, trilha da Mãe d'Água, 2310'53,2"' S - 44 $11^{\prime} 34,3^{\prime \prime}$ W, 43 msm., 10.II.2009, C.E. Jascone 1273 (RFFP); Parque Estadual da Ilha Grande, Vila Dois Rios, Trilha da Jararaca, $23^{\circ} 10^{\prime} 58,1^{\prime \prime} \mathrm{S}$ $44^{\circ} 12^{\prime} 05,1^{\prime \prime} \mathrm{W}, 100 \mathrm{msm}$., 22.V.2010, A.A.M. de Barros 4015 (RFFP). Couratari pyramidata (Vell.) Kunth (Lecythidaceae): Caxadaço, sem data, F. Pinheiro et al. 809 (HB). Coussapoa curranii S.F. Blake (Urticaceae): Maratariz, trilha para o mirante do bananal, 22.IX.2017, M.D.M. Vianna Filho 3001 (HRJ). Cupania concolor Radlk (Sapindaceae): Mirante para Trilha do Saco do Céu, 23'80'36'S - 41'3'34'W, 46 msm, 27.V.2011, D.M. Silva et al. 96 (HB); 15.IX.2012, L.P.G. Rosa s.n. (HRJ 12458). Cupania furfuraceae Radlk (Sapindaceae): 20.VII.2012, L.P.G. Rosa s.n. (HRJ 12459); 17.XI.2014, I.E. Santo et M.F. Castilhor 1204 (HB); 19.XI.2014, I.E. Santo et M.F. Castilhori 1271 (HB). Disciphania hernandia (Vell.) Barneby (Menispermaceae): 11.XI.2011, D.M. Silva 231 (HB); Parque Estadual da Ilha Grande, Vila Dois Rios, Morro do Cavalinho, $23^{\circ} 11.547^{\prime \prime} \mathrm{S}-44^{\circ} 11.638^{\prime \prime} \mathrm{W}$, 157 msm., 28.VI.2015, A.A.M. de Barros 5105 (RFFP). 
Epidendrum hololeucum Barb.Rodr. (Orchidaceae): III.2011, fl., M.R.A Braga et R. Motta 368 (RB). Eugenia bunchosiifolia Nied. (Myrtaceae): Trilha do Cachadaço, 18.II.2001, F.C. Pinheiro 748 (RB). Eugenia malacantha D.Legrand (Myrtaceae): trilha para o Pico do Papagaio, 08.II.2015, A. Giaretta 1491 (SPF). Faramea coerulea (Nees \& Mart.) DC. (Rubiaceae): Parque Estadual da Ilha Grande, Vila Dois Rios, Morro do Cavalinho, $23^{\circ} 11^{\prime} 70,4^{\prime \prime} S$ $-44^{\circ} 11^{\prime} 68,7^{\prime \prime} \mathrm{W}, 136 \mathrm{msm}$., 18.VIII.2012, A.A.M. de Barros 4788 (RFFP). Ficus cyclophylla (Miq.) Miq. (Moraceae): Lagoa Azul, 26.III.2004, B.E. Diaz 1564 (RB). Heteropterys patens (Griseb.) A.Juss. (Malpighiaceae): Parque Estadual da Ilha Grande, Vila Dois Rios, Mata da Jararaca, $23^{\circ} 10^{\prime} 52,92^{\prime \prime} \mathrm{S}-44^{\circ} 12^{\prime} 02,59^{\prime \prime} \mathrm{W}, 170 \mathrm{msm}$., 07.IX.2014, A.A.M. de Barros 5065 (RFFP). Hippeastrum striatum (Lam.) Moore (Amaryllidaceae): Praia de Saco das Palmas para Lopes Mendes, 18.IV.1987, L.C. Giordano et al. 267 (RB). Inga sellowiana Benth. (Fabaceae): Reserva Biológica Estadual da Praia do Sul, sem data, D. Araujo 6217 (RB). Ischnosiphon ovatus Körn (Marantaceae): Parque Estadual da Ilha Grande, Vila Dois Rios, Mata da Represa, $23^{\circ} 10^{\prime} 56,3^{\prime \prime S}-44^{\circ} 12^{\prime} 15,7^{\prime \prime} \mathrm{W}, 136 \mathrm{msm}$., 21.X.2011, A.A.M. de Barros 4414 (RFFP). Maranta subterranea J.M.A.Braga (Marantaceae): Parque Estadual da Ilha Grande, Trilha das Palmeiras, área do Projeto RAPELD - módulo leste, L1-4.500, 23K, 44W 11' 18" 23S 10'23", 193 msm., 09.IV.2016, A.A.M. de Barros 5226 (RFFP); Parque Estadual da Ilha Grande, Vila Dois Rios, Trilha das Palmeiras, área do Projeto RAPELD módulo leste, L1-4.500, 23K, 44W 11' 18" - 23S 10'23", 193 msm., 13.XII.2015, A.A.M. de Barros 5206 (RFFP); Parque Estadual da Ilha Grande, Vila Dois Rios, Mata da Jararaca, $23^{\circ} 11^{\prime} 00,5^{\prime \prime} \mathrm{S}-44^{\circ} 12^{\prime} 04,2^{\prime \prime} \mathrm{W}, 110 \mathrm{msm} ., 15$. XI.2015, A.A.M. de Barros 5131 (RFFP). Melanopsidium nigrum Colla (Rubiaceae): Reserva Ecológica Estadual da Praia do Sul, 21.IX.1999, A. Lobão et al. 464 (RB); Parque Estadual da Ilha Grande, Vila Dois Rios, Mata da Jararaca, $23^{\circ} 10.623^{\prime}$ 'S - 44'12.310'W, 311 msm., 11.IX.2014, L.R. Caires 105 (RFFP); Parque Estadual da Ilha Grande, Vila Dois Rios, Mata da Jararaca, $23^{\circ} 10.626^{\prime} \mathrm{S}-44^{\circ} 12.372^{\prime} \mathrm{W}$, 268 msm., 07.IX.2014, L.R. Caires 88 (RFFP). Meriania glazioviana Cogn. (Melastomataceae): Reserva Biológica Estadual da Praia do Sul, curso superior do Rio Capivari, 13.08.1985, R. Ribeiro 668 (US); Parque Estadual da Ilha Grande, Vila Dois Rios, Represa, 04-III-2002, A.A.M. de Barros 1428 (RB). Meriania longipes Triana (Melastomataceae): Vila Dois Rios, Mata da Jararaca, 22.III.2000, F.C. Pinheiro 367 (RB); Parque Estadual da Ilha Grande, Vila Dois Rios, Trilha da Jararaca, $23^{\circ} 10^{\prime} 58,9^{\prime \prime} \mathrm{S}-44^{\circ} 12^{\prime} 40,2^{\prime \prime} \mathrm{W}, 260$ msm., 17.III.2014, T.S. Mendes 39 (RFFP); Parque Estadual da Ilha Grande, Estrada Vila do Abraão a Vila Dois Rios, área do Projeto RAPELD - módulo Leste, Parcela Britador, L2- 2.500, 23K, $584100 \mathrm{~S}-7439076$ W UTM, 27.IV.2017, A.A.M. de Barros 5368 (RFFP). Miconia gigantea Cogn. (Melastomataceae): Parque Estadual da Ilha Grande, -23.0067 S, -44.3181 O, 05.12.1991, A.T. Silva s.n. (RBR
32976). Micropholis compta Pierre in Urb. (Sapotaceae): sem data, sem coletor (HRJ 11717). Mikania argyreiae DC. (Asteraceae): estrada Praia do Abraão - Colônia Penal, 28.VI.1978, J.P.P. Carauta 2931 (RB); Reserva Biológica Estadual da Praia do Sul, restinga aberta Praia do Sul, 13.VI.1984, D. Pedrosa et H.Q.B. Fernandes 920 (US); Praia do Sul, $1^{\text {a }}$ trilha de entrada (placa da FEEMA), 29.IX.2002, R. Scheel-Ybert et al. 264 (RB). Neomitranthes amblymitra (Burret) Mattos (Myrtaceae): 04.IX.2011, L.P.G. Rosa s.n. (HRJ 12419). Neoregelia hoehneana L.B.Sm. (Bromeliaceae): Restinga Praia do Sul, 13.X.2002, A.F. Nunes-Freitas 62 (RBR); Vila de Dois Rios, Grid da Jararaca, 13.X.2002, A.F. Nunes-Freitas 63 (RBR). Ocotea odorifera (Vell.) Rowher (Lauraceae): 23.VIII.2011, L.P.G. Rosa s.n. (HRJ 12334). Peperomia distachya (L.) A. Dietr. (Piperaceae): Parque Estadual da Ilha Grande, Vila Dois Rios, Mata da Jararaca, 18.I.2002, A.A.M. de Barros 1354 (RFFP). Philodendron curvilobum Schott (Araceae): Reserva Biológica Estadual da Praia do Sul, parcelas do módulo oeste RAPELD, 15.X.2016, A.C.R. Cruz 18 (RBR). Pilocarpus giganteous Engl. (Rutaceae): Parque Estadual da Ilha Grande, Vila Dois Rios, Mata da Jararaca, $23^{\circ} 10.655^{\prime} \mathrm{S}-44^{\circ} 12.284^{\prime} \mathrm{W}, 252 \mathrm{msm}$., 06. VI.2014, L.R. Caires 83 (RFFP). Piper scutifolium Yunck. (Piperaceae): Parque Estadual da Ilha Grande, Vila Dois Rios, Trilha para a Represa, $23^{\circ} 10^{\prime} 94,4^{\prime \prime} \mathrm{S}-44^{\circ} 12^{\prime} 23,9^{\prime}$ 'W, 168 msm., 13.VI.2012, T.S. Mendes 103 (RFFP); Parque Estadual da Ilha Grande, Vila Dois Rios, Trilha da Jararaca, $23^{\circ} 10^{\prime} 97,6^{\prime \prime} \mathrm{S}-44^{\circ} 11^{\prime} 66,8^{\prime \prime} \mathrm{W}, 163 \mathrm{msm}$., 03.IV.2014, G.A. de Queiroz 140 (RFFP). Pleroma thereminiana (DC.) Triana (Melastomataceae): Parque Estadual da Ilha Grande, Vila Dois Rios, Mãe D'água, 20.V.2000, F.C. Pinheiro 419 (RB); Trilha para Represa, 16.XI.2001, A.A.M. de Barros 1156 (RFFP); Cachoeira da Mata da Mãe d'Água, 19.I.2002, A.A.M. de Barros 1373 (RFFP); Trilha da Jararaca, $23^{\circ} 10^{\prime} 58,1^{\prime \prime} \mathrm{S}-4^{\circ} 12^{\prime} 05,1^{\prime \prime} \mathrm{W}, 100 \mathrm{msm}$., 22.V.2010, A.A.M. de Barros 4023 (RFFP). Plinia edulis (Vell.) Sobral: 19.VII.2011, L.P.G. Rosa s.n. (HRJ 12423); Parnaioca, 24.I.2018, I. Souza et A.C.P. Couto 225 (EFC). Rhipsalis oblonga Loefgr. (Cactaceae): III.1915, P.C. Porto 109 (RB); Parque Estadual da Ilha Grande, Trilha T-16 sentido Vila Dois Rios - Praia da Parnaioca, $23^{\circ} 10^{\prime} 91,1^{\prime \prime} \mathrm{S}$

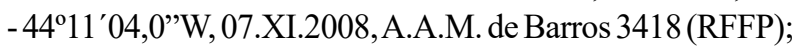
Parque Estadual da Ilha Grande, Praia de Lopes Mendes, $23^{\circ} 09^{\prime} 98,2^{\prime \prime}$ S - 4407'97,6”W, 19.VIII.2012, A.A.M. de Barros 4815 (RFFP); Estrada Vila do Abraão a Vila Dois Rios, área do Projeto RAPELD - módulo Leste, Parcela Curva Maravilha, L2-4.500, 23K, -23,17273 S -44,179019 W UTM, 05.VIII.2017, A.A.M. de Barros 5482 (RFFP). Roupala sculpta Sleumer (Proteaceae): Parque Estadual da Ilha Grande, 23.XII.1991, A.T. Silva s.n. (RBR 32998). Rudgea macrophylla Benth (Rubiaceae): Reserva Biológica Estacional da Praia do Sul, 12.X.1990, R. Ribeiro \& W.L. Araujo 1905 (RB). Rudgea jasminoides (Cham.) Müll. Arg. (Rubiaceae): 10.XII.2011, L.P.G. Rosa s.n. (HRJ 12231). Smilax spicta Vell. (Smilacaceae): Parque Estadual da Ilha Grande, Vila Dois Rios, Trilha da Jararaca, 
$23^{\circ} 10^{\prime} 58,1^{\prime \prime S}-44^{\circ} 12^{\prime} 05,1$ 'W, 100 msm., 22.V.2010, A.A.M. de Barros 4020 (RFFP). Solanum argenteum Dunal (Solanaceae): Parque Estadual da Ilha Grande, Trilha T-16 sentido Vila Dois Rios - Praia de Parnaióca, 02.III.2002, A.A.M. de Barros 1400 (RFFP); Barra Grande, 17.V.2002, C.C. Zysko 281 (RB); Parque Estadual da Ilha Grande, Vila Dois Rios, Foz do Rio Barra Grande, 2311'19,7'S

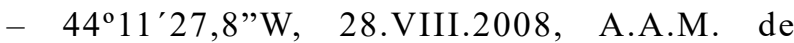
Barros 3276 (RFFP); trilha para Caxadaço, 31.V.2009, C.Y'G. Manão 509 (RB); Estrada Vila Dois Rios - Abraão, 23.X.2009, C.Y'G. Manão 620 (RB); Parque Estadual da Ilha Grande, Vila Dois Rios, Trilha para Praia do Caxadaço (T-15), em ruínas de antigas habitações, 2310'58, 'S 4410'45,3”W, 145msm., 17.VIII.2012, A.A.M. de Barros 4759 (RFFP); Parque Estadual da Ilha Grande, Vila Dois Rios, Trilha para Cachoeira da Mãe d'Água, Vale atrás do bambuzal, $23^{\circ} 10^{\prime} 85,2^{\prime \prime S}-44^{\circ} 11^{\prime} 58,1^{\prime \prime W}, 5 \mathrm{msm}$., 25.X.2012, T.S. Mendes 14 (RFFP); Parque Estadual da Ilha Grande, Vila Dois Rios, Trilha para Cachoeira da Mãe d'Água, Vale atrás do bambuzal, 2311'01,2"S 44²'00,9'W, 57msm., 25.XI.2012, T.S. Mendes 17 (RFFP); 12.XII.2013, P.R.A. de Jesus s.n. (HRJ 12454); Parque Estadual da Ilha Grande, Vila Dois Rios, Trilha para Cachoeira da Mãe d'Água, Mata do Vale, $23^{\circ} 10^{\prime} 85,2^{\prime \prime} \mathrm{S}$ -44¹1'58, 1'W, 5 msm., 11.II.2014, T.S. Mendes 30 (RFFP). Solanum carautae Carvalho (Solanaceae): estrada entre a Praia do Abraão e a Colônia Penal, lado nordeste da ilha, 28.VI.1978, J.P.P. Carauta 2940 (RB); caminho para a Praia de Palmas, 20.IV.1980, M.R. Barbosa 31 (R, RB); Próximo Simão Dias, 20.III.1992, R. Ribeiro s.n. (RB 304008); 08.II.2012, S.J. Silva Neto s.n. (HRJ 12474). Solanum mauritianum Scop. (Solanaceae): estrada entre a Praia do Abrãao e a Colônia Penal, lado nordeste da ilha, 28.VI.1978, J.P.P. Carauta 2907 (RB). Solanum pseudoquina A.St.-Hil. (Solanaceae): 02.IV.1985, D.S.D. Araújo 6772 (RB); 28.XI.1989, D.S.D. Araújo 9021 (RB); Parque Estadual da Ilha Grande, Unidade amostral Britador, 29.XI.1991, A.T. Silva s.n. (RBR 33018); 06.VIII.1992, R. Ribeiro s.n. (RB 304004). Stelis palmeiraensis
Barb.Rodr. (Orchidaceae): sem data, M.R.A. Braga 359(RB). Tachigali denudata (Vogel) Oliveira-Filho (Fabaceae): 20.VII.2012, L.P.G. Rosa s.n. (HRJ 12325). Virola bicuhyba (Schott ex Spreng.) Warb (Myristicaceae): L.P.G. Rosa s.n. (HRJ 12357). Voyria aphylla (Jacq.) Pers. (Gentianaceae): Reserva Biológica Estadual da Praia do Sul, sem data, C. Farney 2356 (RB); Parque Estadual da Ilha Grande, Vila Dois Rios, trilha da Parnaioca, 02.III.2001, P.W. Feteira 137 (RFFP); Parque Estadual da Ilha Grande, Vila Dois Rios, Mata da Mãe d'Água, 19.I.2002, A.A.M. de Barros 1369 (RFFP); Reserva Biológica da Praia do Sul, Restinga da Praia do Leste, 14.II.2006, L.J.S. Pinto 823 (RFFP); Parque Estadual da Ilha Grande, Trilha entre a Praia de Lopes Mendes e a Praia do Pouso - T11, 2309'62,4”S - 4408'28,6”W, 15.VIII.2010, A.A.M. de Barros 4192 (RFFP); Parque Estadual da Ilha Grande, Vila Dois Rios, Morro do Cavalinho, 2311'31.51's 4411'37.88'W, 157 msm., 11.XII.2015, A.A.M. de Barros 5187 (RFFP). Vriesea rodigasiana E.Morren (Bromeliaceae): Restinga da Praia do Sul, 20.II.2003, A.F. Nunes-Freitas 804 (RBR); Reserva Biológica Estadual da Praia do Sul, parcelas do módulo oeste do RAPELD, 15.X.2016, A.C.R. Cruz 20 (RBR); A.C.R. Cruz 28 (RBR). Vriesea rubyae E.Pereira (Bromeliaceae): Pico do Papagaio, sem data, R. Moura 973 (RBvb). Xylopia brasiliensis Spreng.: 14.VI.2012, L.P.G. Rosa 2 (HRJ); Parque Estadual da Ilha Grande, Vila Dois Rios, Mata da Jararaca, $23^{\circ} 10^{\prime} 52,92^{\prime} \mathrm{S}$ - 4412'02,59'W, 170 msm., 07.IX.2014, A.A.M. de Barros 5063 (RFFP); Vila Dois Rios, área acima da Cachoeira da Mãe d'Água, Mata da Represa, 23⒒005'S - 44 ${ }^{\circ} 12.225^{\prime} \mathrm{W}, 155$ msm., 09.IX.2014, D.N.S. Machado 458 (RFFP); Estrada Vila do Abraão a Vila Dois Rios, área do Projeto RAPELD - módulo Leste, Parcela Britador, L2- 2.500, 23K, 74S 23' 27" - 58W 24' 36", 11.III.2017, A.A.M. de Barros 5366 (RFFP). Wittrockia superba Lindm. (Bromeliaceae): Parque Estadual da Ilha Grande, Vila Dois Rios, Grid da Mãe d'água, 05.VII.2001, A.F. Nunes-Freitas 28 (RB, RBR); Parque Estadual da Ilha Grande, Lagoa Verde, VI.2004,A.F. Nunes-Freitas 94 (RBR). 